\title{
Wavelet Analysis and Neural Networks for Bearing Fault Diagnosis
}

\author{
Khalid Al-Raheem \\ Caledonian College of Engineering \\ Oman
}

\section{Introduction}

The manufacturing productivity can be achieved through the availability of the physical resources and improved manufacturing methods and technology. The operational availability of various industrial systems can be increased by adopting efficient maintenance strategies. An ideal maintenance strategy meets the requirements of machine availability and operational safety at minimum cost.

Today, most maintenance actions are carried out by either corrective (run to failure) or preventive (scheduled or predetermined) strategy. In Corrective Maintenance (CM) the components are maintained after obvious faults or actual breakdown has occurred. With this maintenance strategy the associated costs are usually high due to the production losses, fault occurrence damages, restoring equipment until is being used at failure condition, and the safety/health hazards presented by the fault. However, the Preventive Maintenance (PM) approach has been developed to overcome the CM deficiencies. Traditionally, PM is a time driven process which is performed at regular time intervals, commonly termed the maintenance cycle, regardless of the components actual condition, in order to prevent component or systems breakdown. For example, changing the car engine oil at every 5000 KMs traveled distance, where no concern as to the actual condition and performance capability of the replaced oil.

Over recent decades some industries have started to employ a second type of PM actions in a predictive manner, where the actual machinery condition is the key indicator for the maintenance schedule and appropriate maintenance tasks (condition driven), therefore referred to as Condition Based Maintenance (CBM).

In CBM systems, the machinery condition assessment is achieved by acquiring and interpreting the actual machine data continuously with an aim to provide lead-time and required maintenance prior to predicted failure or loss of efficiency (Just-In-Time maintenance). The application of the CBM approach provides the ability to optimize the availability of process machinery, and greatly reduce the cost of maintenance. The CBM system also provides the means to improve product quality, productivity, profitability, safety and overall effectiveness of manufacturing and production plant.

The tools and techniques employed in the field of the CBM systems include: measurement and sensor technology, modeling of failure mechanisms, failure forecasting techniques, 
diagnostic and prognostic software, communication protocols, maintenance software applications and computer networking technologies.

The concept of condition monitoring consists of a selection of measurable parameters which correlate with the health or condition of a machine, and an interpretation of the collected data to determine the machinery fault existence and identify specific components (e.g. gear set, bearings) in the machine that are degrading, Detection mode. Moreover, the condition monitoring activities may include: specify the component failure causes, Diagnostic mode, and estimate the remaining life of the monitored component, Prognostic mode. For example, the particles content in the lubricant oil is an indicator of the machine's wearing condition. By setting warning limits for the particles content of the lubricant a preventive action can be taken before the catastrophic failure occurs. With more detailed analysis of the measurement the nature of the problem can be identified, and lead to the diagnosis of the problem. The level of automation in assessing the machine condition can vary from human visual inspection to fully automated systems with sensors, data manipulation, condition monitoring, diagnosis, and prognosis.

Various parameters e.g. vibration, temperature, lubricant oil analysis, thermography, electric current, acoustic emission, etc, and different data analysis techniques have been applied and developed to provide significant data analysis for CM, which include:

Time domain methods: using different statistical indicators such as, Root Mean Square (RMS), Peak value, Kurtosis, etc. (Orhan et al. .2006) and (Tandon , 1994).

Frequency domain methods: such as Fourier Transform (FT) spectrum (Reeves, 1994), envelope detection (Weller, 2004), Cepstrum, etc.

Time-Frequency methods: which include Short Time Fourier Transform (STFT) (Thanagasundram and Schlindwein, 2006), Wavelet Analysis (WA) (Peng and Chu, 2004) (Wang and Gao , 2003), (Junsheng et al. , 2007 ) and (Kahaei et al. , 2006), etc.

Adaptive noise cancellation methods: such as Adaptive Noise Canceling (ANC), and Adaptive Line Enhancer (ALE), etc. (Khemili and Chouchane, 2005)

Bearing failures represent a high percentage of the breakdowns in the rotating machinery and result in serious problems, mainly in places where machines are rotating at constant and high speeds, not only because of the large quantity of them installed in rotating machinery, but also due to their role in relation to product quality.

This chapter presents the application of wavelet analysis combined with artificial neural networks as an automatic rolling bearing fault detection and diagnosis, with applied to both simulated (modeling) and real (measured) bearing vibration signals.

The chapter has been divided into two parts, in the first part the application of the wavelet analysis as a bearing fault detection/diagnosis technique is presented. The wavelet fault detection techniques are based on the use of the autocorrelation of the wavelet de-noised vibration signal and the wavelet envelope power spectrums for the identification of bearing fault frequencies.

The second part includes the application of wavelet analysis as a feature extraction method combined with the neural network classifier for automatic detection and diagnosis of the rolling bearing fault. 


\section{Rolling element bearings}

Bearings permit a smooth low friction motion between two surfaces (usually a shaft and housing) loaded against each other. The terms rolling-contact bearing, antifriction bearing, and rolling bearing are all used to describe that class of bearing in which the main load is transferred through elements in rolling contact rather than in sliding contact (sliding bearings).

The basic concept of the rolling element bearing is simple. If loads are to be transmitted between surfaces in relative motion in a machine, the action can be achieved in the most effective way if the rolling elements are interposed between the sliding members. The frictional resistance encountered in sliding is then largely replaced by much smaller resistance associated with rolling, although this arrangement is accompanied with high stresses in the contact regions of effective load transmission.

The standard configuration of a rolling element bearing is an assembly of the outer and inner rings which enclose the rolling elements such as balls (ball bearings), Figure 1a, and cylindrical rollers (roller bearings), Figure $1 \mathrm{~b}$, and the cage or separator which assures annular equidistance between the rolling elements and prevents undesired contacts and rubbing friction among them. Some bearings also have seals as integrated components.

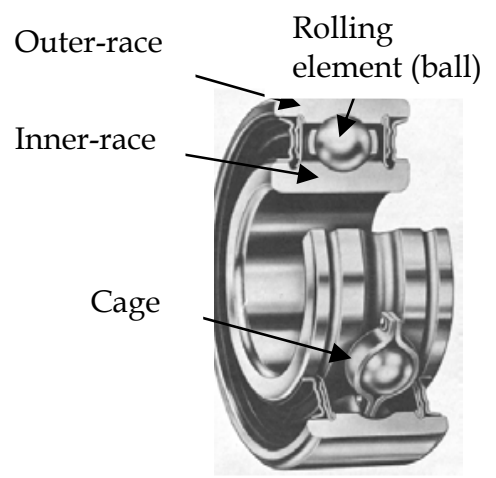

(a)

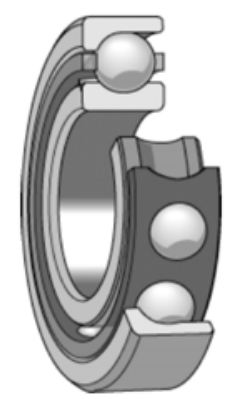

(c)

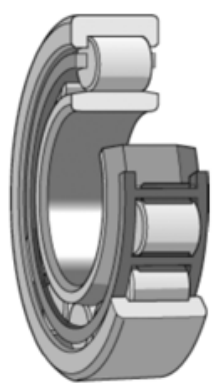

(b)

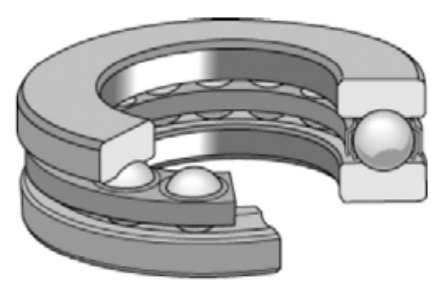

(d)

Fig. 1. Rolling element bearing (a) deep groove ball bearing, (b) roller bearing (c) angular contact ball bearing, and (d) thrust bearing (Harris, 2001). 
The rolling surfaces on the rings are referred to as raceways. The number of balls is defined as $N_{b}$, their diameter as $D_{b}$. The pitch diameter or the diameter of the cage is designated $D_{p}$. The point of contact between a ball and the raceways is characterized by the contact angle $a$, Figure 2.
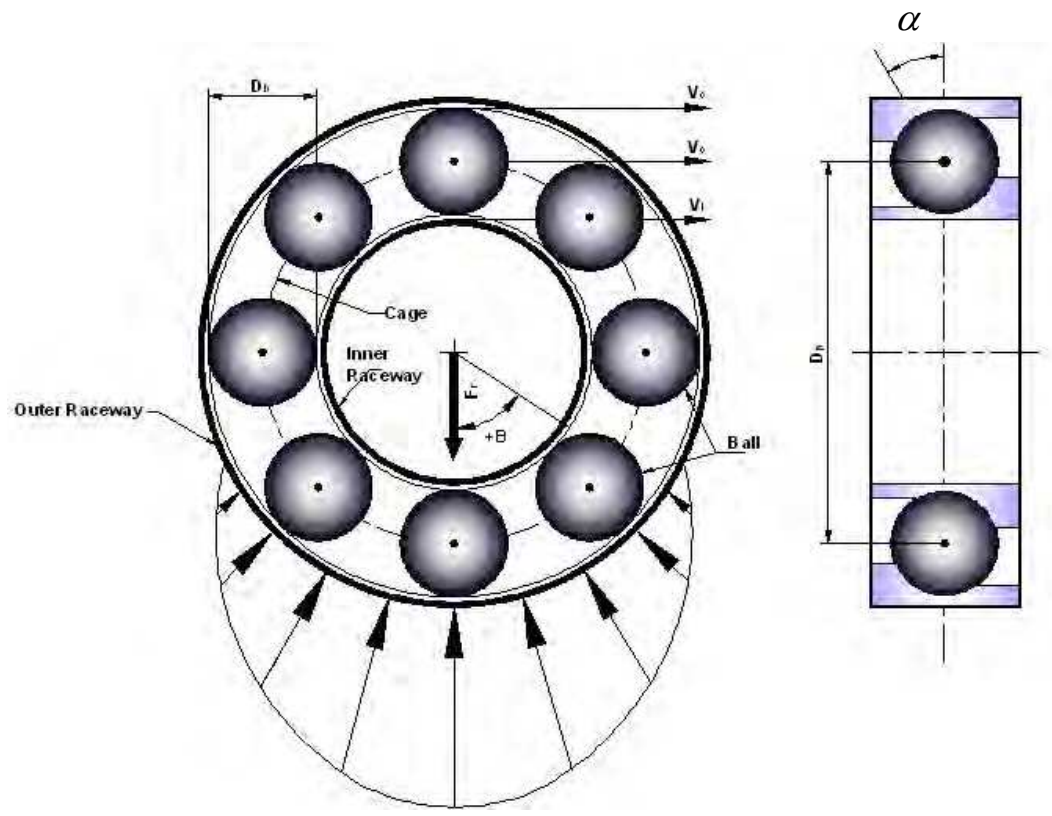

Fig. 2. Rolling element bearing basic geometry and velocities.

The rolling bearings that support loads perpendicular to their axis of rotation are called radial bearing. However, the bearings which support loads parallel to the axis of rotation are termed thrust bearings (the contact angle exceeding 45\%), Figure 1d. Angular contact bearings have one ring shoulder removed; this may be from the inner or outer ring, Figure 1c. This allows a larger ball complement than found in comparable deep groove bearings, giving a greater load capacity. Speed capacity of angular contact bearings is also greater than deep groove ball bearing. The normal angular contact bearings have a contact angle which does not exceed $40^{\circ}$. Angular contact bearings support a combination of radial and thrust loads or heavy thrust loads depending on the contact angle. A single angular contact bearing can be loaded in one thrust direction only.

Because roller bearings have a greater rolling surface area in contact with inner and outer races, they generally support a greater load than comparably sized ball bearings. The small contact area (point contact) in the ball bearing compared with the roller bearing (line contact) leads to more stress concentration and is more affected by the fatigue failure during the bearing rotation. Moreover, the angular contact ball bearing can easily separate its components (separable) to introduce the artificial faults. Based on that the angular contact ball bearings have been used in this research for fault detection. 


\section{Bearing fault diagnosis using wavelet analysis}

The Wavelet Transform (WT) coefficients are analyzed in both the time and frequency domains. In the time domain the autocorrelation of the wavelet de-noised signal is applied to evaluate the period of the fault pulses using the impulse wavelet as a wavelet base function. However, in the frequency domain the wavelet envelope power spectrum has been used to identify the fault frequencies with the single sided complex Laplace wavelet as the mother wavelet function.

\subsection{Wavelet de-noising method}

\subsubsection{Impulse wavelet function}

The WT is the inner product of a time domain signal with the translated and dilated waveletbase function. The resulting coefficients reflect the correlation between the signal and the selected wavelet-base function. Therefore, to increase the amplitude of the generated wavelet coefficients related to the fault impulses, and to enhance the fault detection process, the selected wavelet-base function should be similar in characters to the bearing impulse response generated by the presence of a bearing incipient fault. Based on that, the investigated waveletbase function is denoted as the impulse-response wavelet and given by,

$$
\psi(t)=A \quad e^{-\frac{\beta}{\sqrt{1-\beta^{2}}} \omega_{c} t} \sin \left(\omega_{c} t\right)
$$

Where $\beta$ is the damping factor that controls the decay rate of the exponential envelope in time and hence regulates the resolution of the wavelet, simultaneously it corresponds to the frequency bandwidth of the wavelet in the frequency domain, $\omega_{c}$ determining the number of significant oscillations of the wavelet in the time domain and correspond to the wavelet centre frequency in frequency domain, and $A$ is an arbitrary scaling factor. Figure 3 shows the proposed wavelet and its power spectrum.

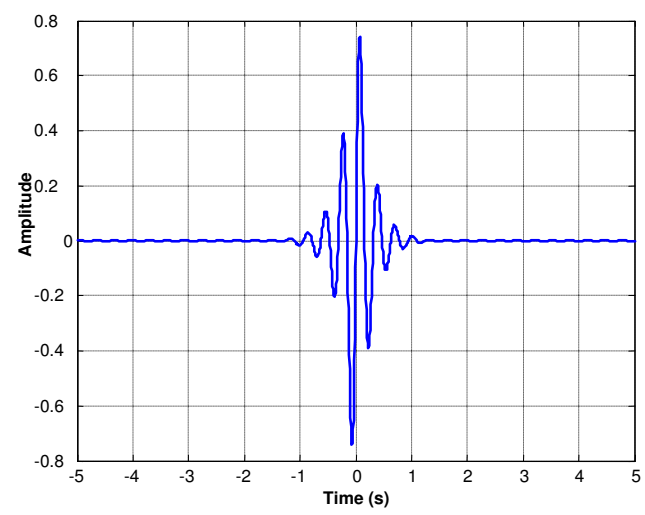

(a)

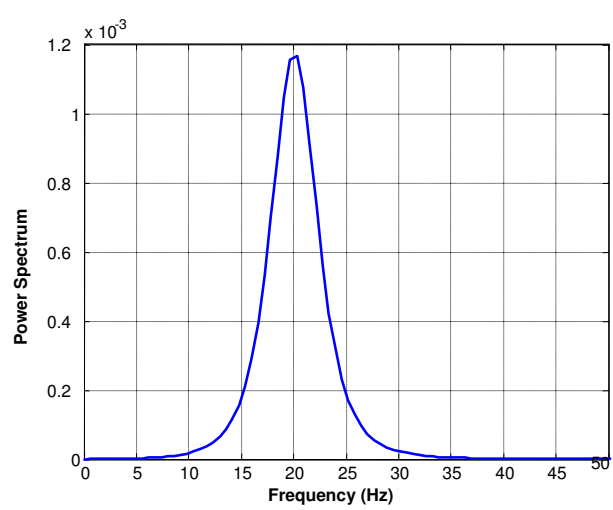

(b)

Fig. 3. (a) the impulse wavelet time waveform, (b) its FFT-spectrum. 


\subsubsection{The wavelet de-noising autocorrelation technique}

The proposed wavelet de-noising technique consists of the following steps:

a. Optimize the wavelet shape parameters ( $\beta$ and $\omega_{c}$ ) based on maximization of the kurtosis of the signal- wavelet inner product.

It is possible to find optimal values of $\beta$ and $\omega_{c}$ for a given vibration signal by adjusting the time-frequency resolution of the impulse wavelet to the decay rate and frequency of the impulses to be extracted.

Kurtosis is an indicator that reflects the "peakiness" of a signal, which is a property of the impulses and also it measures the divergence from a fundamental Gaussian distribution. A high kurtosis value indicates a high impulsive content of the signal with more sharpness in the signal intensity distribution. Figure 4 shows the kurtosis value and the intensity distribution for a white noise signal, pure impulsive signal, and impulsive signal mixed with noise.

The objective of the impulse wavelet shape optimization process is to determine the wavelet shape parameters $\left(\beta\right.$ and $\left.\omega_{c}\right)$ which maximize the kurtosis of the wavelet transform output;

$$
\operatorname{Optimal}\left(\beta, \omega_{c}\right)=\max \cdot\left[\frac{\sum_{n=1}^{N} W T^{4}\left(x(t), \psi_{\beta, \omega_{c}}(t)\right)}{\left[\sum_{n=1}^{N} W T^{2}\left(x(t), \psi_{\beta, \omega_{c}}(t)\right)\right]^{2}}\right]
$$

The genetic algorithm with specifications shown in Table 1 is used to optimize the wavelet shape parameters using Equation 2 as the GA fitness function. A flowchart of the algorithm is shown in Figure 5.

\begin{tabular}{|c|c|}
\hline Population size & 10 \\
\hline Number of generations & 20 \\
\hline Termination function & Maximum generation \\
\hline Selection function & Roulette wheel \\
\hline Cross-over function & Arith-crossover \\
\hline Mutation function & Uniform mutation \\
\hline
\end{tabular}

Table 1. The applied GA parameters.

b. Apply the wavelet de-noising technique: which consists of:

1. Perform a wavelet transform for the bearing vibration signal $x(t)$ using the optimized wavelet,

$$
W T\{x(t), a, b\}=<\psi_{a, b} . x(t)>=\frac{1}{\sqrt{a}} \int x(t) \Psi_{a, b}^{*}(t) d t
$$

where $<.>$ indicates the inner product, and the superscript asterisk ${ }^{\prime * 1}$ indicates the complex conjugate. The $\psi_{a, b}$ is a family of daughter wavelets derived from the mother wavelet $\psi(t)$ by continuously varying the scale factor $a$ and the translation parameter $b$. The factor $1 / \sqrt{a}$ is used to ensure energy preservation. 

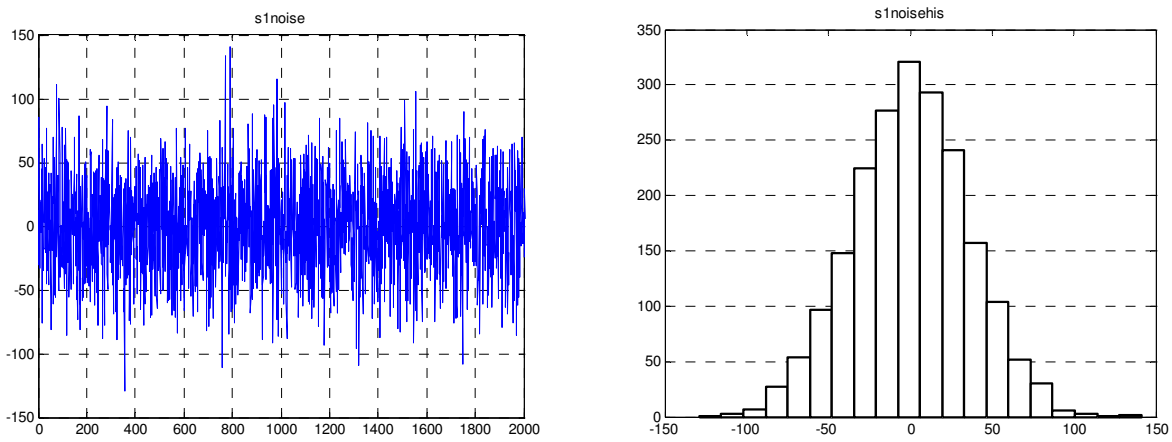

(a)
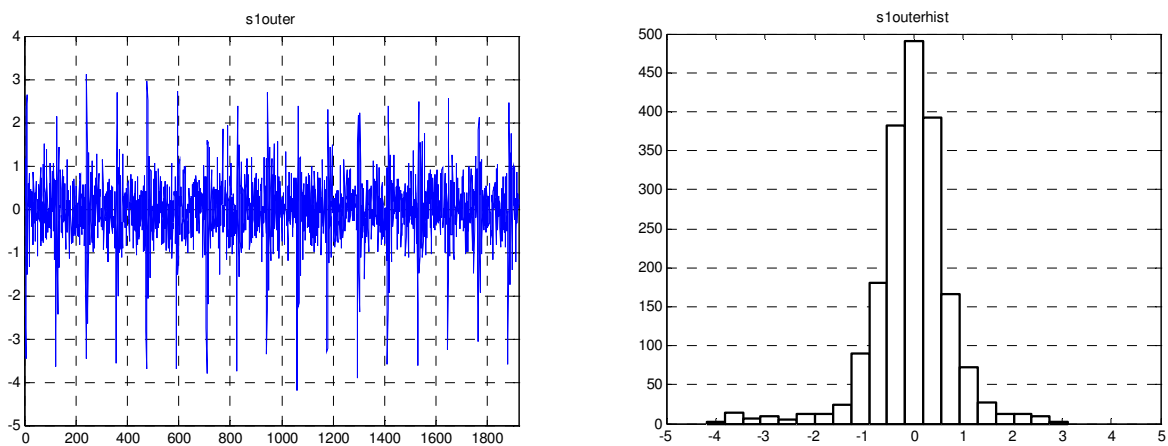

(b)
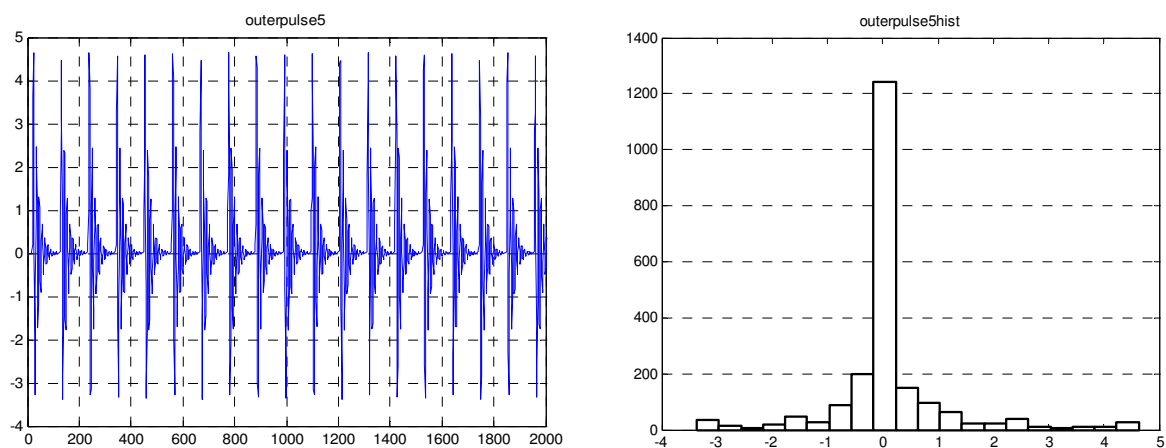

(c)

Fig. 4. (a) The noise signal (kurtosis=3.0843), (b) the overall vibration signal (kurtosis=7.7644), and (c) outer-race fault impulses (kurtosis=8.5312), with the corresponding intensity distribution curve. 


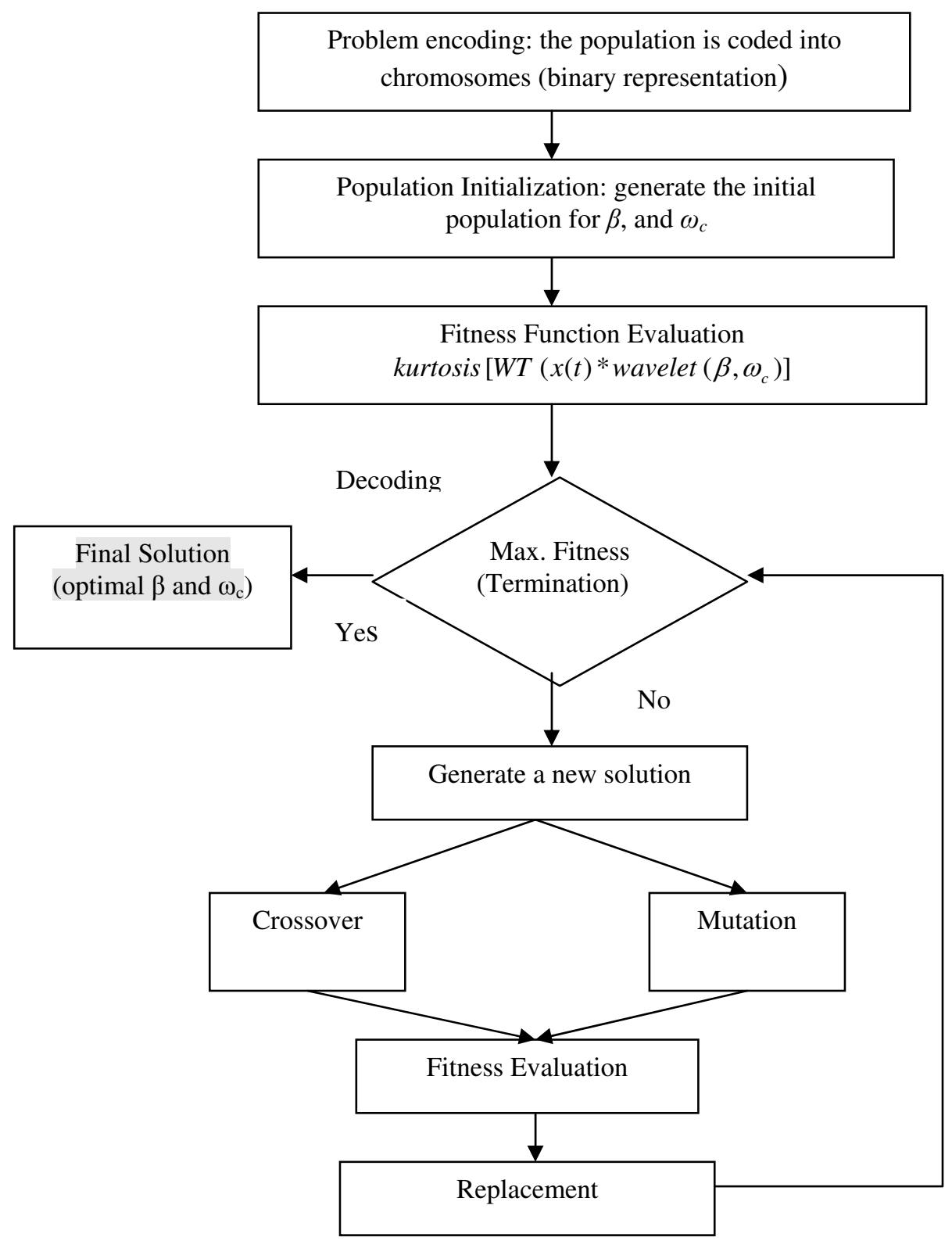

Fig. 5. Wavelet shape parameters optimization process using GA. 
2. Shrink the wavelet coefficients expressed in Equation 3 by soft thresholding,

$$
W T^{\text {soft }}= \begin{cases}0 & |W T|<t h r \\ \operatorname{sign}(W T)(W T-t h r) & |W T|>t h r\end{cases}
$$

using soft-threshold function (thr) proposed by YANG and REN (2004),

$$
\text { thr }=e^{-\left[\operatorname{Max}(|W T(a, b)|)^{\xi}\right]}-e^{-\left[\operatorname{Max}(|W T(a, b)|)^{\xi}\right]}
$$

where $\xi>0$ is parameter governing the shape of the threshold function.

3. Perform the inverse wavelet transform to reconstruct the signal using the shrunken wavelet coefficients.

$$
{ }^{*} x(t)=C_{g}^{-1} \int_{-\infty}^{\infty} W T^{s o f t}(a, t) \frac{d a}{a^{3 / 2}}
$$

c. Evaluate the auto-correlation function $R_{x}(\tau)$ for the de-noised signal $x^{*}(t)$ to estimate the periodicity of the extracted impulses

$$
R_{x}(\tau)=E[\stackrel{*}{x}(t) \cdot \stackrel{*}{x}(t+\tau)]
$$

where $\tau$ is the time lag, and $E[]$ denotes ensemble average value of the quantity in square brackets.

\subsubsection{Applications for bearing fault detection}

To demonstrate the performance of the proposed approach, this section presents several application examples for the detection of localized bearing defects. In all the examples, the impulse wavelet has been used as the wavelet base-function. The wavelet parameters (damping factor and centre frequency) are optimized based on maximizing the kurtosis value for the wavelet coefficients as shown in Figure 6.

To evaluate the performance of the proposed method, the autocorrelation functions of the optimized impulse wavelet, impulse wavelet with non-optimized parameters, and the widely used Morlet wavelet are carried out and shown in Figure 7. The comparison of Figures $7 \mathrm{a}, \mathrm{b}$ and $\mathrm{c}$, shows the increased effectiveness of the optimized impulse wavelet over non-optimized impulse and Morlet wavelets for extraction of the bearing fault impulses and corresponding periodicity. Consequently, the performance of the bearing fault diagnosis process has been improved using the proposed technique.

\section{(a) Simulated vibration data}

For a rolling element bearing with specifications as given in Table 2, the calculated BCFs (appendix A) for a shaft rotational speed of $1797 \mathrm{rev} / \mathrm{min}$ are $107.36 \mathrm{~Hz}$ and $162.18 \mathrm{~Hz}$ for outer and inner-race faults respectively. Figure 8 (a and d) shows the time domain waveform of the simulated signals for the rolling bearing with outer and inner-race faults based on the bearing vibration mathematical model (Khalid F. Al-Raheem et al. 2008). The 
result of the wavelet de-noising method (wavelet transform, shrink the wavelet coefficients and take the inverse wavelet transform) for the rolling bearing with outer and inner race faults using the optimized impulse wavelet and the corresponding autocorrelation function are displayed in Figure 8 (b, c e and f). The results show that the signal noise has been diminished and the impulses generated by the faulty bearing are easy to identify in the wavelet de-noised signal. The impulse periodicity of $0.00975 \mathrm{sec}\left(F_{B P O}=102.564 \mathrm{~Hz}\right)$ for outer-race fault and $0.006167 \mathrm{sec}\left(F_{B P I}=162.153 \mathrm{~Hz}\right)$ for inner-race fault are effectively extracted through the auto-correlation of the de-noised signal and exactly match the theoretical calculation of the BCF.

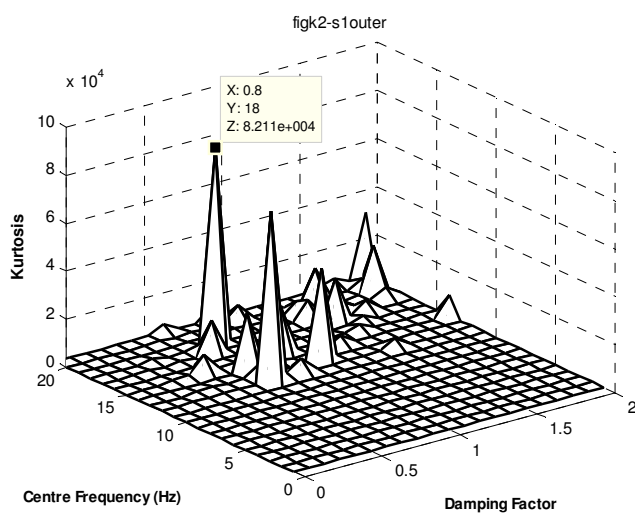

(a)

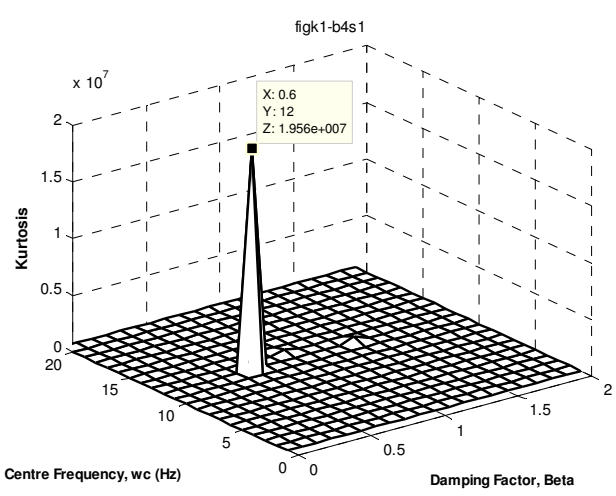

(b)

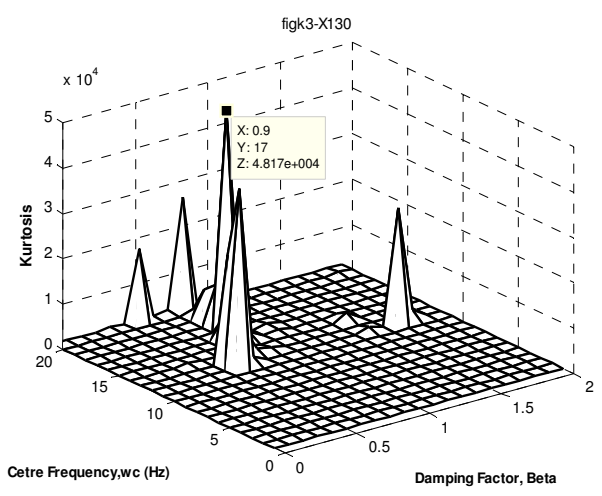

(c)

Fig. 6. The optimal values for Laplace wavelet parameters based on maximum kurtosis for,(a) simulated outer-race fault,(b) the measured outer-race fault,(c) the CWRU vibration data. 


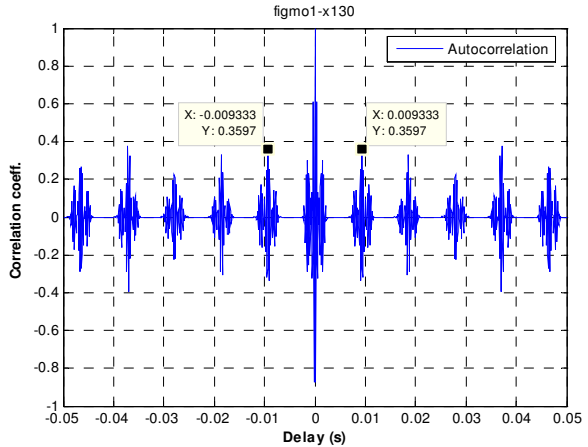

(a)

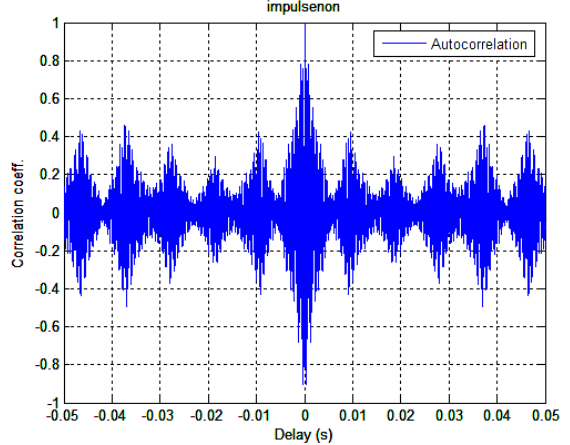

(b)

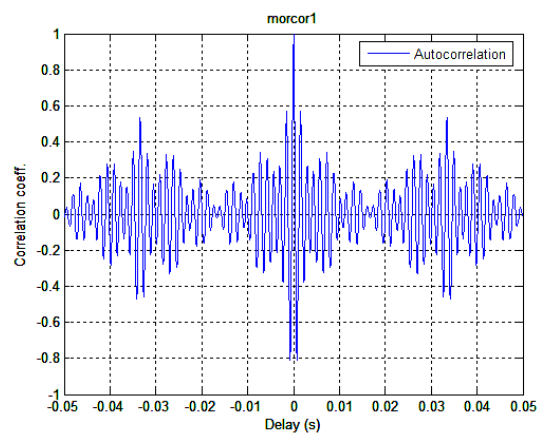

(c)

Fig. 7. The autocorrelation function of the wavelet de-noised outer-race fault signal using (a) optimized impulse-wavelet, (b) non-optimized impulse-wavelet, and (c) Morlet-wavelet.

\section{(b) Experimental vibration data}

Based on the bearing parameters given in Table 2, the calculated outer race fault characteristic frequencies $\left(F_{B P O}\right)$ for different shaft speeds are shown in Table 2.

\begin{tabular}{|c|c|c|c|c|c|c|}
\hline \multirow{2}{*}{$\begin{array}{c}\mathrm{D}_{\mathrm{p}} \\
(\mathrm{mm})\end{array}$} & $\begin{array}{c}\mathrm{D}_{\mathrm{b}} \\
(\mathrm{mm})\end{array}$ & \multirow{2}{*}{$\begin{array}{c}\mathrm{N}_{\mathrm{b}} \\
(\mathrm{ball})\end{array}$} & $\begin{array}{c}\mathrm{a} \\
(\text { degree })\end{array}$ & \multicolumn{3}{|c|}{ Defect Frequencies (multiple of running speed, Hz) } \\
\cline { 5 - 7 } & & & & Outer-race & Inner-race & $\begin{array}{c}\text { Rolling } \\
\text { element }\end{array}$ \\
\hline 51.16 & 11.9 & 8 & 0 & 3.069 & 4.930 & 4.066 \\
\hline
\end{tabular}

Table 2. Bearing specification: Deep groove ball bearing RHP LJT $1^{1 / 4}$.

Figures 9 to 11 show the application of the proposed wavelet de-noising technique for the rolling bearing with outer-race fault at different shaft rotational speed. The bearing fault impulses and corresponding periodicity are easily discerned in the wavelet de-noised signal and the de-noised autocorrelation function, respectively. Comparison of Figures 9 to 11 
shows the sensitivity of the proposed de-noising technique to the variation of the $F_{B P O}$ as a result of variation in the shaft rotational speed as listed in Table 3.

\begin{tabular}{|c|c|c|c|}
\hline $\begin{array}{c}\text { Shaft Speed } \\
(\mathrm{rev} / \mathrm{min})\end{array}$ & $\begin{array}{c}\text { Calculated } F_{B P O} \\
(\mathrm{~Hz})\end{array}$ & $\begin{array}{c}\text { Extracted Period } \\
(\mathrm{sec})\end{array}$ & $\begin{array}{c}\text { Extracted } F_{B P O} \\
(\mathrm{~Hz})\end{array}$ \\
\hline 983.887 & 50.32 & 0.020310 & 49.236 \\
\hline 2080.28 & 106.4 & 0.009297 & 107.561 \\
\hline 3541.11 & 181.12 & 0.005391 & 185.493 \\
\hline
\end{tabular}

Table 3. The calculated and extracted $\left(\mathrm{F}_{\mathrm{BPO}}\right)$ at different shaft rotational speeds.
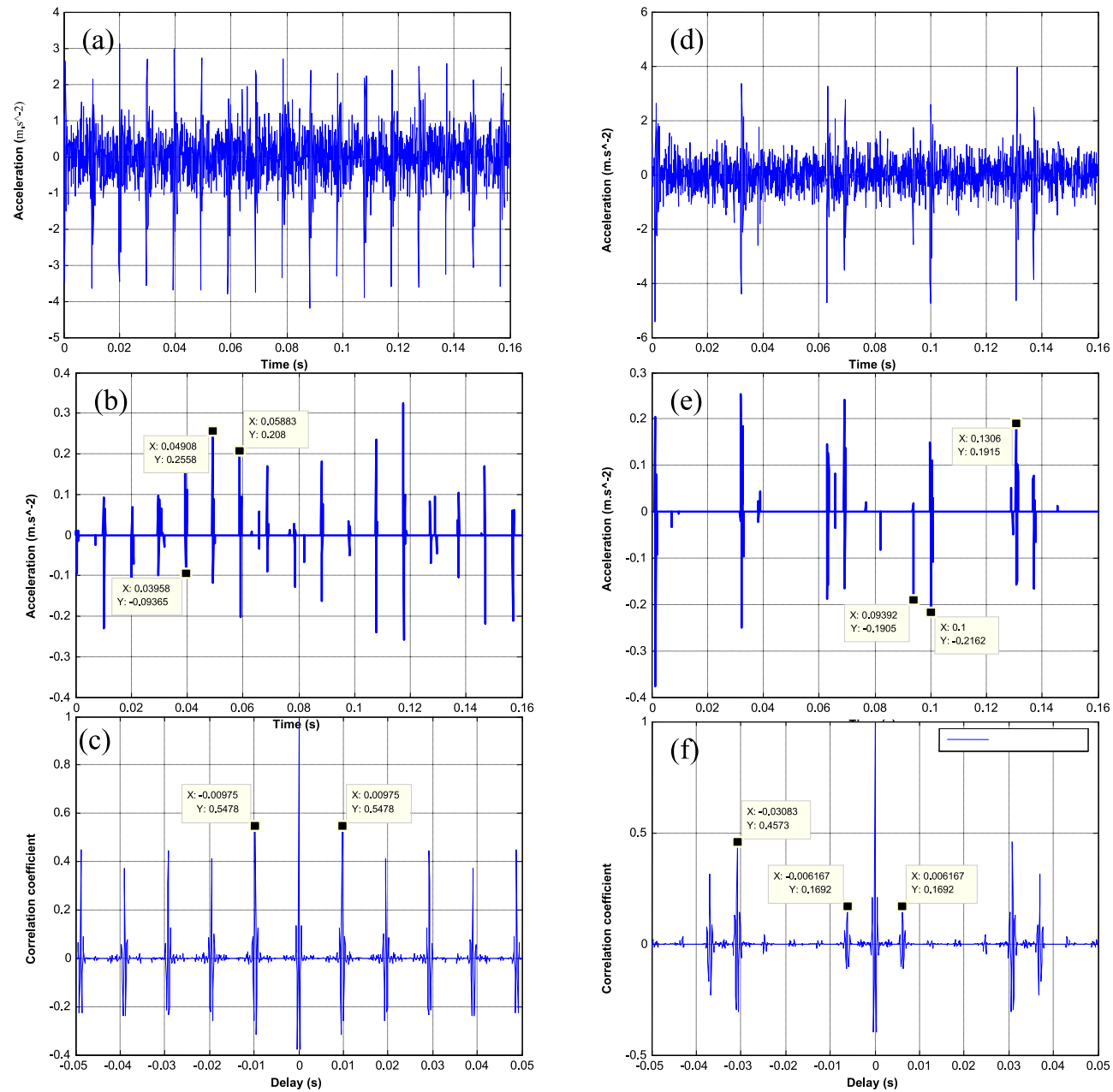

Fig. 8. The simulated vibration signal, the corresponding wavelet de-noised signal and the auto-correlation function $R_{x}(\tau)$ for bearing with outer-race fault $(a, b$ and $c)$, Inner-race fault (d, e and f) respectively. 


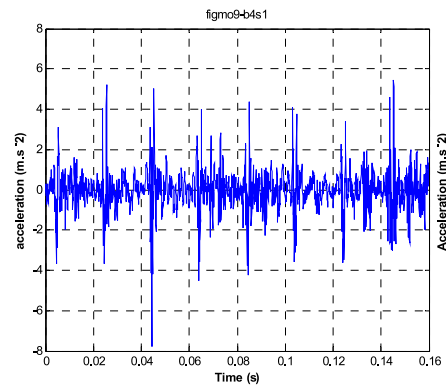

(a)

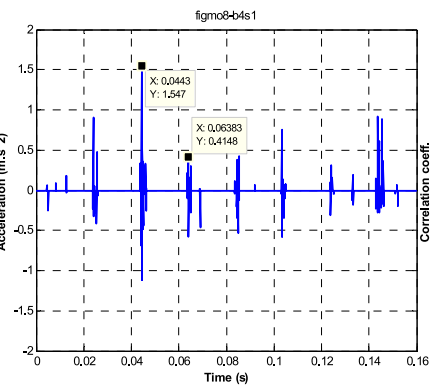

(b)

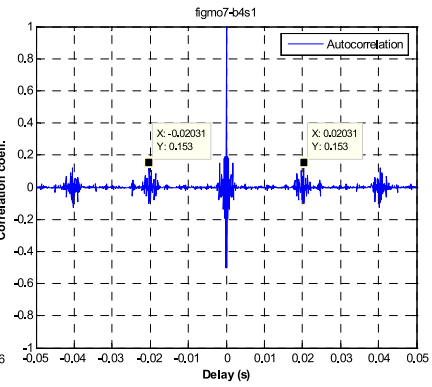

(c)

Fig. 9. (a) the collected vibration signal, (b) the corresponding wavelet de-noised signal, and (c) the auto-correlation function, for bearing with outer-race fault at shaft rotational speed of $983.887 \mathrm{rev} / \mathrm{min}$.

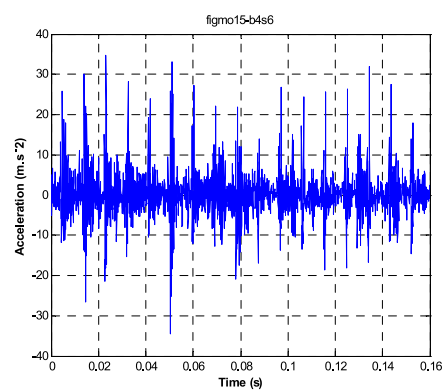

(a)

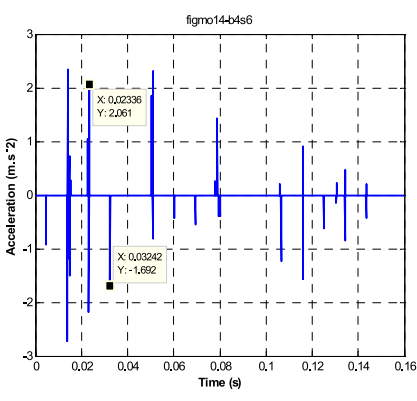

(b)

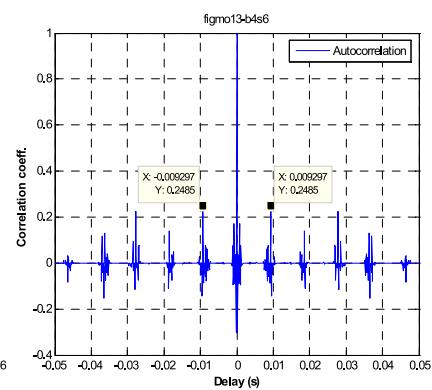

(c)

Fig. 10. (a) the collected vibration signal, (b) corresponding wavelet de-noised signal, and (c) auto-correlation function, for bearing with outer-race fault at shaft rotational speed of $2080.28 \mathrm{rev} / \mathrm{min}$.

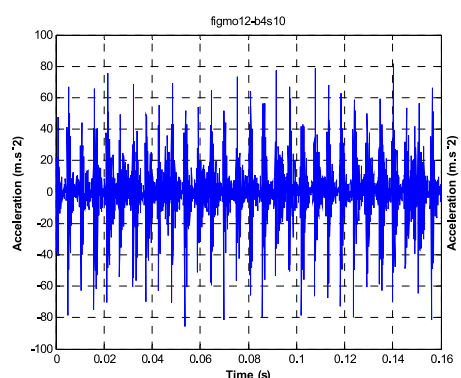

(a)

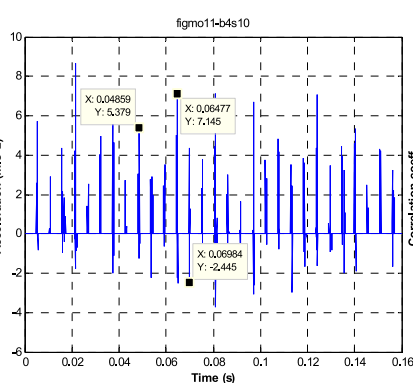

(b)

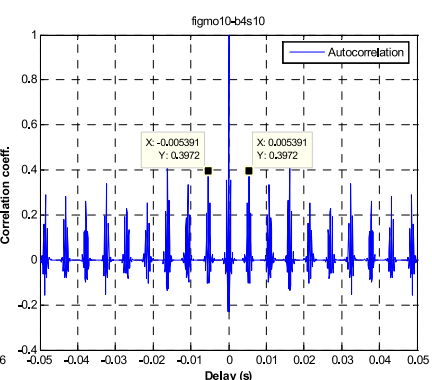

(c)

Fig. 11. (a) the collected vibration signal, (b) corresponding wavelet de-noised signal, and (c) auto-correlation function, for rolling with outer-race fault at shaft rotational speed of $3541.11 \mathrm{rev} / \mathrm{min}$. 


\section{(c) CWRU vibration data}

The vibration data for deep groove ball bearings (bearing specification shown in Table 4) with different faults were obtained from the Case Western Reserve University (CWRU) website (Bearing Data Center, seeded fault test data, $h t t p: / / w w w . e e c s . c a s e . e d u /$ ).

\begin{tabular}{|l|l|l|l|l|l|l|}
\hline $\mathrm{D}_{\mathrm{p}}$ & $\mathrm{D}_{\mathrm{b}}$ & $\mathrm{N}_{\mathrm{b}}$ & $\mathrm{a}$ & \multicolumn{3}{|c|}{ Defect Frequencies (multiple of running speed, $\mathrm{Hz})$} \\
\cline { 5 - 6 }$(\mathrm{mm})$ & $(\mathrm{mm})$ & $($ ball $)$ & $($ degree $)$ & Outer-race & Inner-race & Rolling element \\
\hline 39.04 & 7.94 & 9 & 0 & 3.5858 & 5.4152 & 4.7135 \\
\hline
\end{tabular}

Table 4. Bearing specification: Deep groove ball bearing SKF 6205.

At a shaft rotational speed of $1797 \mathrm{rev} / \mathrm{min}$, the calculated BCF for the bearing specifications given in Table 4, are $107.36 \mathrm{~Hz}$ for an outer-race fault and, $162.185 \mathrm{~Hz}$ for an inner-race fault. The time course of the vibration signals for bearing with outer and inner race faults, the corresponding wavelet de-noised signal and the auto-correlation function are depicted in Figure 12. The autocorrelation functions of the de-noised signal reveal a periodicity of $0.009333 \mathrm{sec}\left(F_{B P O}=107.14 \mathrm{~Hz}\right)$ and $0.006167 \mathrm{sec}\left(F_{B P I}=162.153 \mathrm{~Hz}\right)$ for outer and inner race fault respectively, which are very close to the calculated $\mathrm{BCF}$.

\subsection{The wavelet envelope power spectrum}

To avoid the wavelet admissibility condition (e.g. double sided wavelet function) which is essential in the inverse wavelet transforms (Mallat, 1999). And to be able to use a single side wavelet function which provides more similarity with the bearing fault pulses. A second approach for bearing fault detection based on the analysis of the wavelet coefficients is developed in this section. The WT coefficients using a single-sided function so called Laplace wavelet have been analyzed in frequency domain using a novel wavelet envelope power spectrum technique.

\subsubsection{Laplace wavelet function}

The Laplace wavelet is a complex, single side damped exponential function formulated as an impulse response of a single mode system to be similar to data features commonly encountered in health monitoring tasks. It has been applied to the vibration analysis of an aircraft for aerodynamic and structural testing (Lind and Brenner, 1998), and to diagnose the wear of the intake valve of an internal combustion engine (Yanyang et al., 2005).

The Laplace wavelet is a complex, analytical and single-sided damped exponential given by,

$$
\begin{array}{lll}
\Psi(t)=A e^{-\left(\frac{\beta}{\sqrt{1-\beta^{2}}}+j\right) \omega_{c} t} & \text { if } & t \geq 0 \\
\Psi(t)=0 & \text { where } & t<0
\end{array}
$$

Where $\beta$ is the damping factor and $\omega_{c}$ is the wavelet centre frequency. Figure 13 shows the Laplace wavelet, its real part, imaginary part, and spectrum. The wavelet shape parameters $\beta$ and $\omega_{c}$ have been optimized using GA based on the maximization of the kurtosis value, Equation 2. 

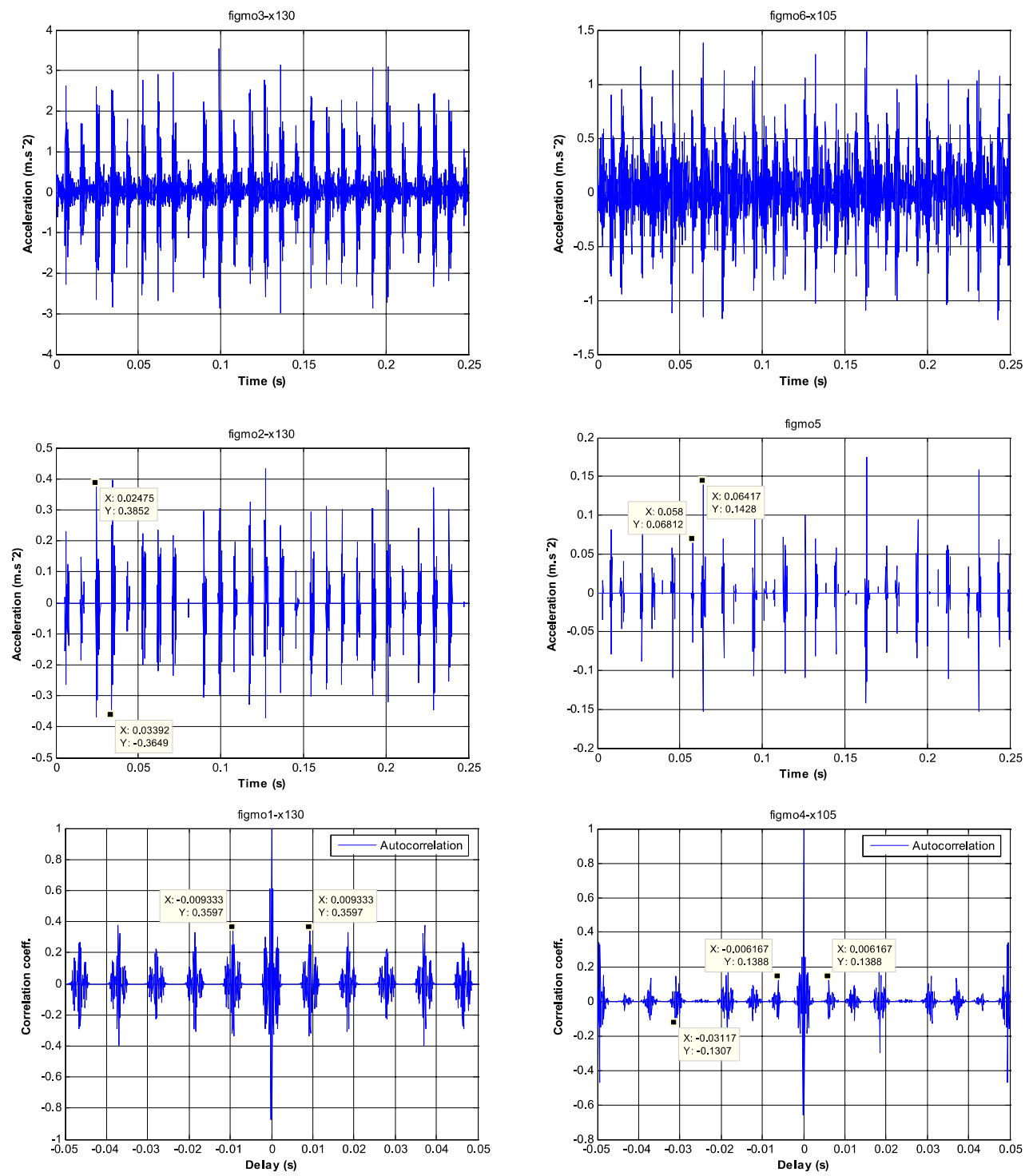

(a)

(b)

Fig. 12. The CWRU collected vibration signal, corresponding wavelet de-noised signal and auto-correlation function, respectively for bearing with (a) outer-race fault, and (b) innerrace fault. 


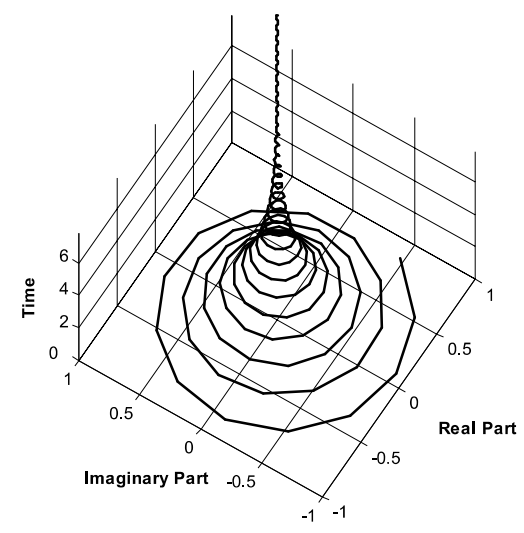

(a)

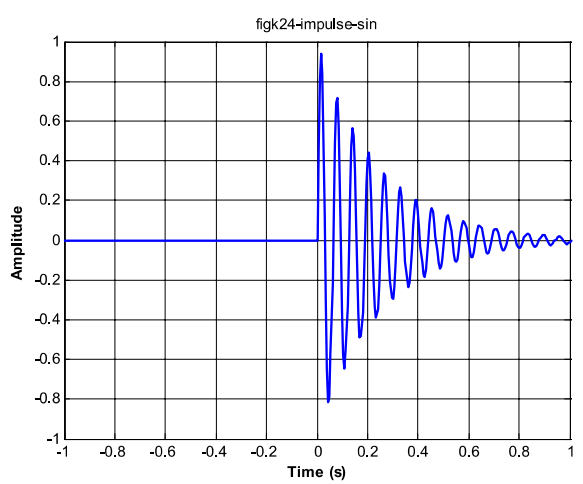

(c)

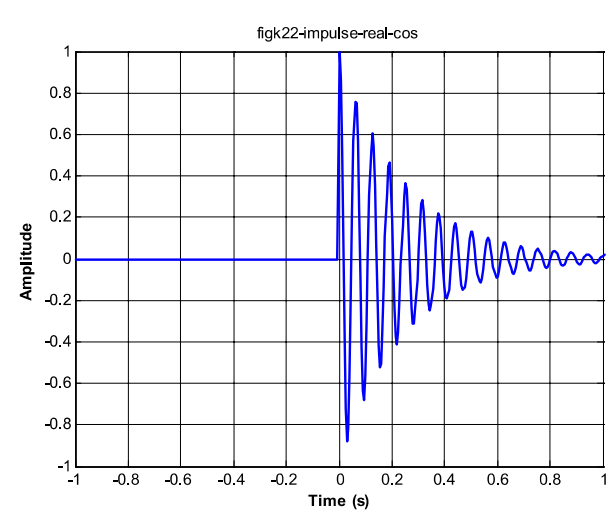

(b)

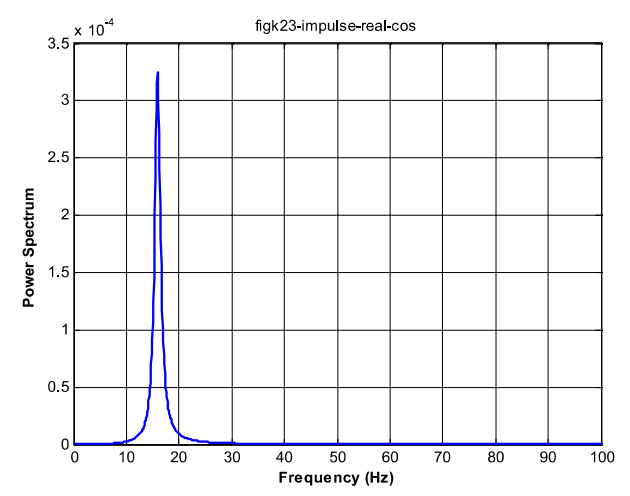

(d)

Fig. 13. (a) the Laplace wavelet, (b) the real part, (c) the imaginary part, and (d) wavelet spectrum.

To show the effectiveness of the proposed Laplace wavelet over the widely used Morlet wavelet, Figure 14 shows the scale-kurtosis distribution of the wavelet transform using Morlet and Laplace wavelets respectively, for different bearing conditions. The comparison of the two wavelets indicates the high sensitivity of the Laplace wavelet over the Morlet wavelet for bearing fault diagnosis. 


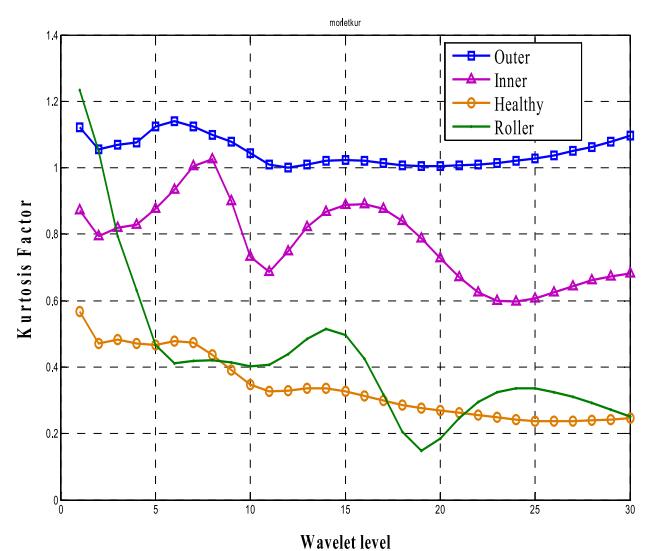

(a)

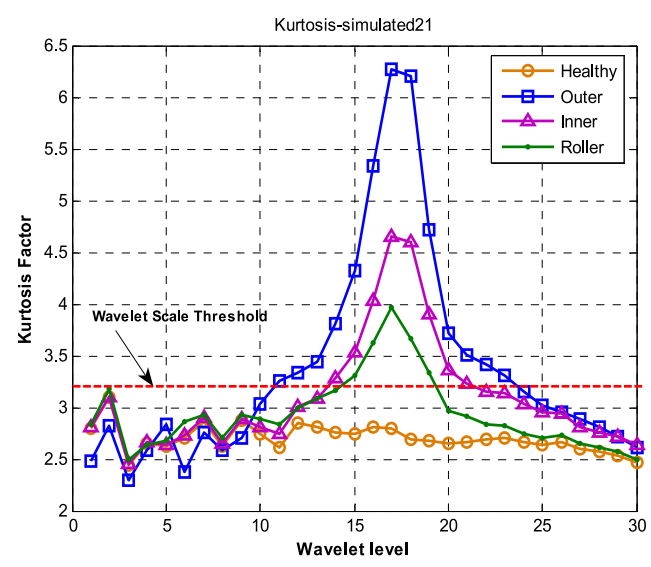

(b)

Fig. 14. The Kurtosis distribution for the wavelet transforms scales using (a) Morlet wavelet, and (b) Laplace wavelet.

\subsubsection{Enveloped wavelet power spectrums}

The vibration signal of a faulty rolling bearing can be viewed as a carrier signal at a resonant frequency of the bearing housing (high frequency) modulated by a decaying envelope. The frequency of interest in the detection of bearing defects is the modulating frequency (low frequency). The goal of the enveloping approach is to replace the oscillation caused by each impact with a single pulse over the entire period of the impact.

The WT of a finite energy signal $x(t)$, with the mother wavelet $\psi(t)$, is the inner product of $x(t)$ with a scaled and conjugate wavelet $\psi_{\mathrm{a}, \mathrm{b}}^{*}$.

Since the analytical and complex wavelet is employed to calculate the wavelets transform, the result of the wavelet transform is also an analytical signal,

$$
\begin{aligned}
W T\{x(t), a, b\} & =<x(t), \psi_{a, b}(t)>=\frac{1}{\sqrt{a}} \int x(t) \Psi_{a, b}^{*}(t) d t \\
& =\operatorname{Re}[W T(a, b)]+j \operatorname{Im}[W T(a, b)]=A(t) e^{i \theta(t)}
\end{aligned}
$$

The time-varying function $A(t)$ is the instantaneous Enveloped Wavelet Transform (EWT) which extracts the slow time variation of the signal (modulating frequency) is given by,

$$
A(t)=E W T(a, b)=\sqrt{\{\operatorname{Re}[W T(a, b)]\}^{2}+\{\operatorname{Im}[W T(a, b)]\}^{2}}
$$

To extract the frequency content of the enveloped correlation coefficients, the scale Wavelet Power Spectrum (WPS) (energy per unit scale) is given by, 


$$
W P S(a, \omega)=\int_{-\infty}^{\infty}|S E W T(a, \omega)|^{2} d \omega
$$

where SEWT $(a, \omega)$ is the Fourier Transform of $\operatorname{EWT}(a, b)$.

The total energy of the signal $x(t)$,

$$
\text { TWPS }=\int|x(t)|^{2} d t=\frac{1}{2 \pi} \int W P S(a, \omega) d a
$$

\subsubsection{Implementation of WPS for bearing fault detection}

To demonstrate the performance of the proposed approach, this section presents several application examples for the detection of localized bearing defects. In all the examples, the Laplace wavelet is used as a WT base-function. The wavelet parameters (damping factor and centre frequency) are optimized based on maximizing the kurtosis value for the wavelet coefficients.

\section{(a) Simulated vibration data}

Using a rolling element bearing with specification shown in Table 2, the scale-wavelet power spectrum comparison for the Laplace-wavelet and widely used Morlet wavelet was carried out, Figure 15. It can be found that the amplitude of the power spectrum is greater for the faulty bearing than the normal one, and the power spectrum is concentrated in the scale interval of [15-20] for the Laplace-wavelet compared with the distributed power spectrum over a wide scale range for the Morlet wavelet. That shows the improved effectiveness of the Laplace wavelet over the Morlet wavelet for bearing fault impulses extraction.

The FFT-Spectrum, envelope spectrum using Hilbert Transform and the Laplace wavelet transform envelope spectrum for the simulated outer-race, inner-race and rolling element faults vibration signals at rotational speed of $1797 \mathrm{rev} / \mathrm{min}$, are shown in Figure 16. The results show that the BCFs are unspecified in the FFT-Spectrum and are not clearly defined in the envelope power spectrum but are clearly identified in the Laplacewavelet power spectrum for both outer, inner race and rolling element faults, Figure 17.

The TWPS effectively extracts the fault frequencies of $105.5 \mathrm{~Hz}, 164.1 \mathrm{~Hz}$ and 141.4 with their harmonics for outer-race, inner-race and rolling element faults, respectively, which are very close to the calculated frequencies $\left(F_{B P O}=107.364 \mathrm{~Hz}, F_{B P I}=162.185 \mathrm{~Hz}\right.$ and $2 F_{B}=141.169$ $\mathrm{Hz}$ ). The side bands at the rotational speed can be recognized for inner race and rolling element faults as a result of amplitude modulation.

To evaluate the robustness of the proposed technique to extract the BCF for different signal to noise ratio (SNR), and randomness in the impulses period $(\tau)$ as a result of slip variation, Figure 18 shows the TWPS for outer-race fault simulated signals for different values of $\mathrm{SNR}$, and $\tau$ as a percentage of the pulse period $(T)$. 

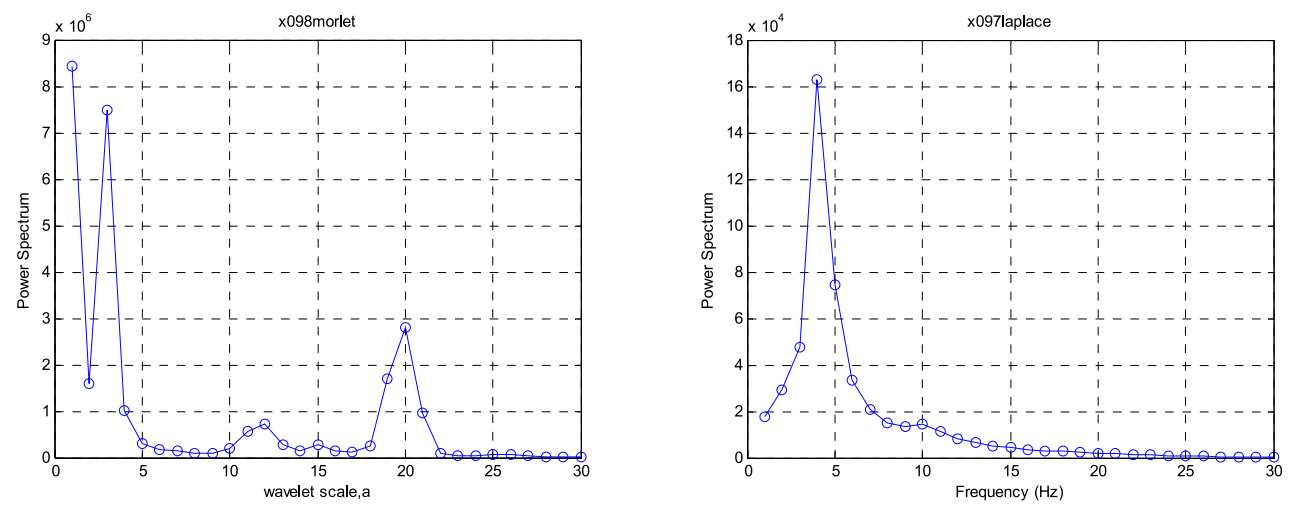

(New bearing)
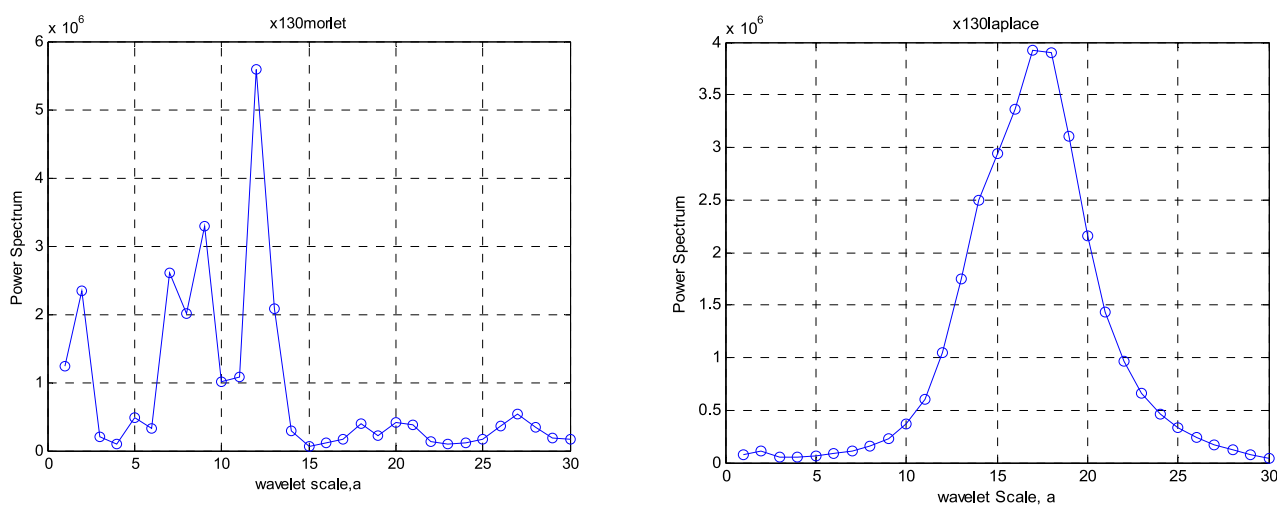

(Outer-race defective bearing)

(a)

(b)

Fig. 15. The wavelet-level power spectrum using (a) Morlet-wavelet, (b) Laplace-wavelet for new and outer-race defective bearing. 

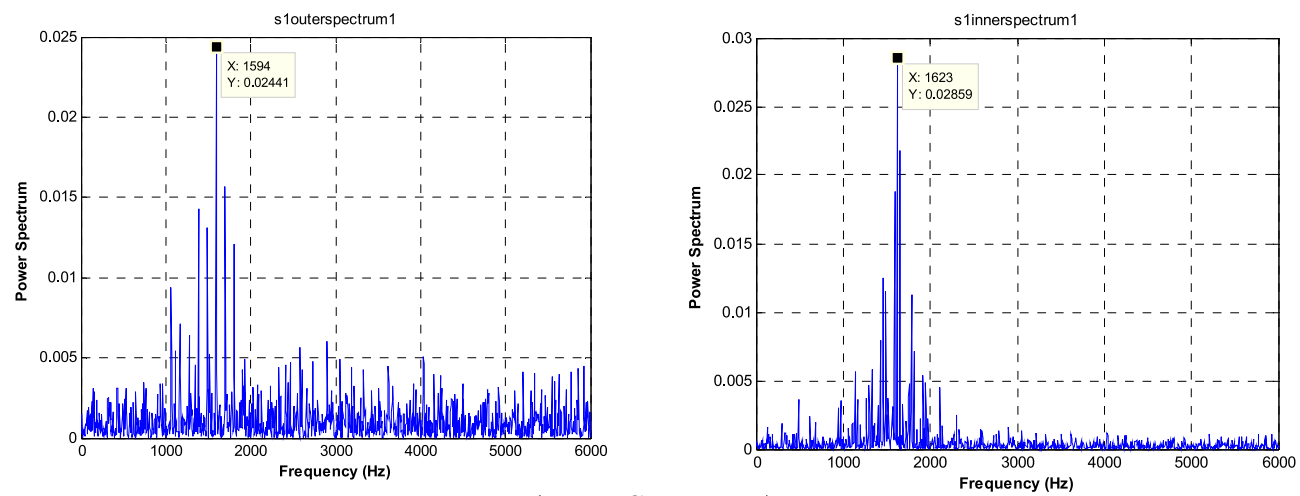

(FFT- Spectrum)
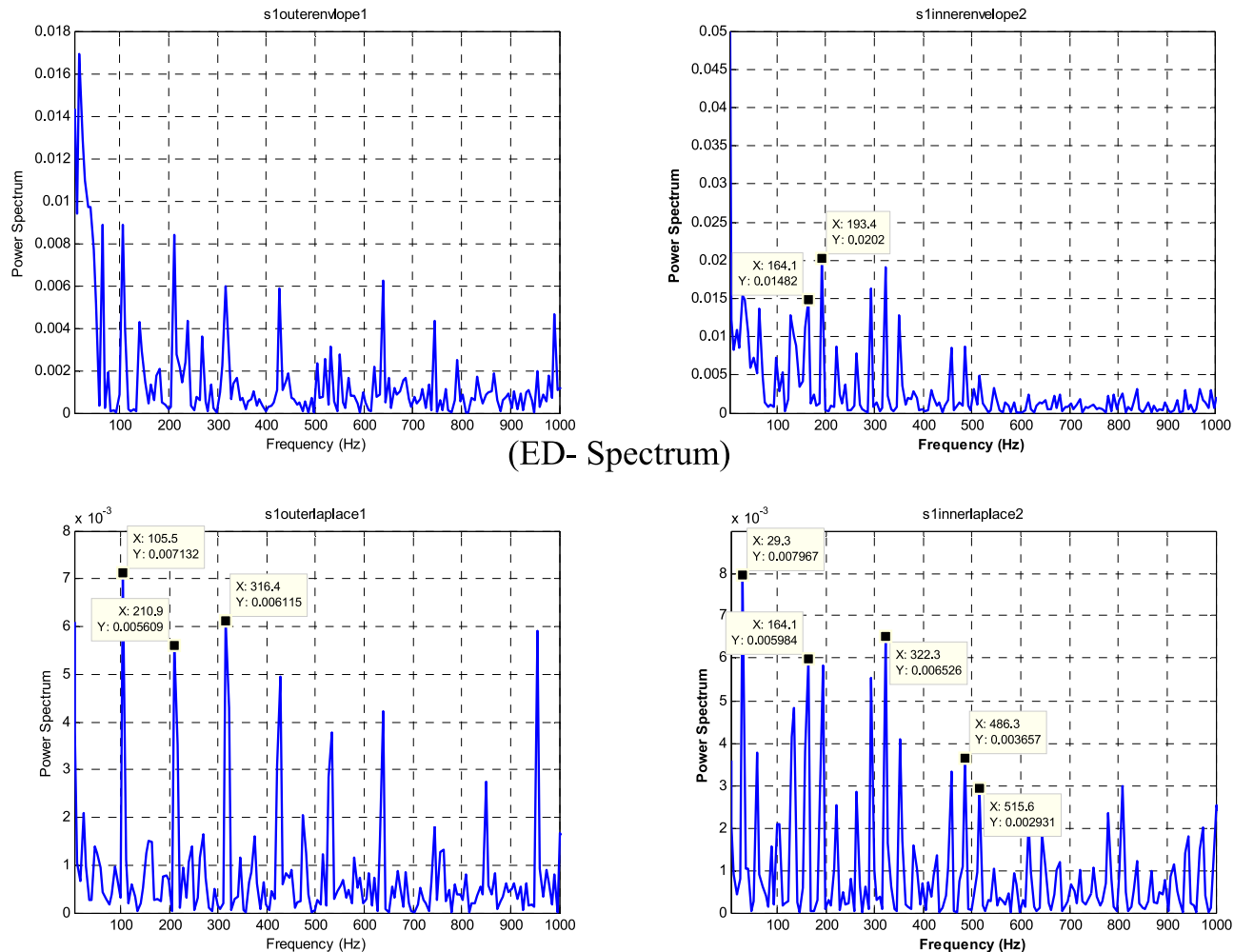

(Laplace wavelet-Spectrum)

(a)

(b)

Fig. 16. The simulated vibration signal power spectrum, envelope power spectrum, and Laplace-wavelet transform power spectrum respectively, for rolling bearing with (a) Outerrace fault and, (b) Inner-race fault. 


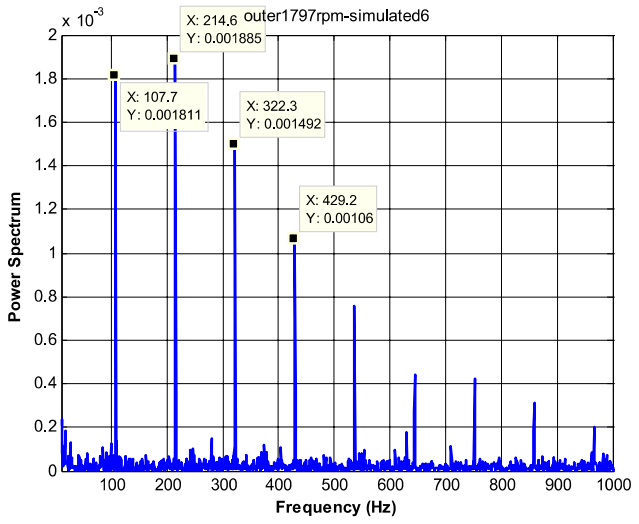

(a)

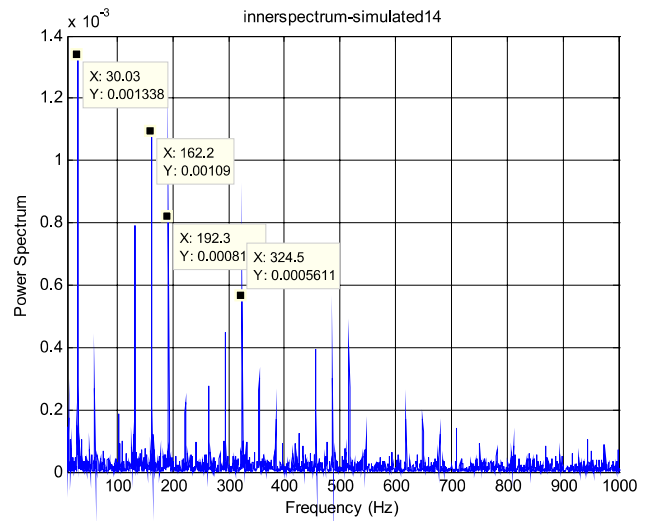

(b)

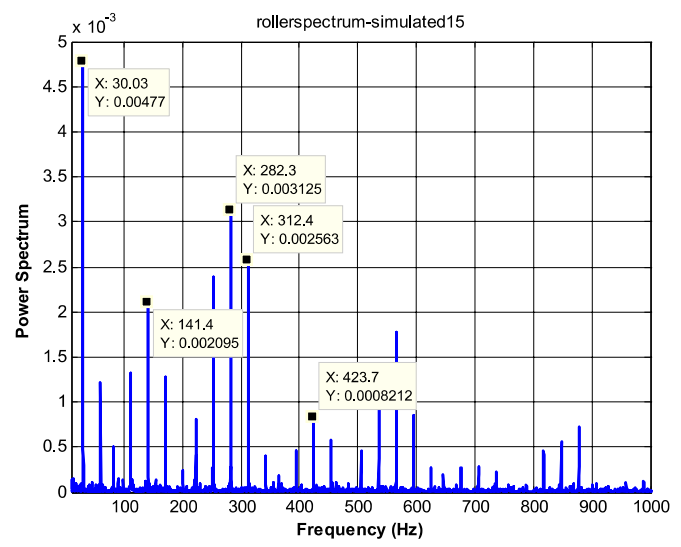

(c)

Fig. 17. The Laplace envelope spectrum of the simulated vibration signal for bearing with (a) outer-race fault, (b) inner-race fault, and (c) rolling element fault, at speed of $1797 \mathrm{rev} / \mathrm{min}$. 


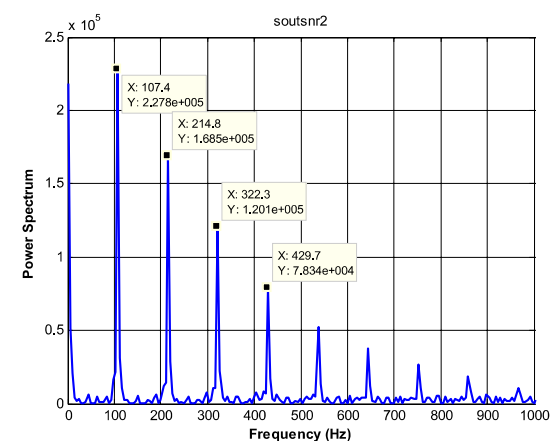

$(\mathrm{SNR}=3.165 \mathrm{~dB})$

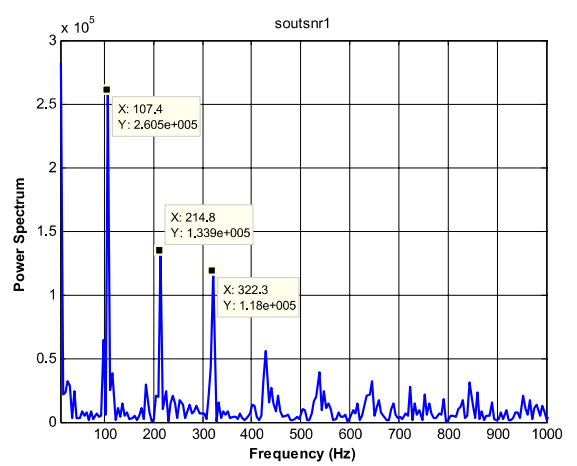

$(\mathrm{SNR}=\mathbf{0 . 6 4 8 8})$

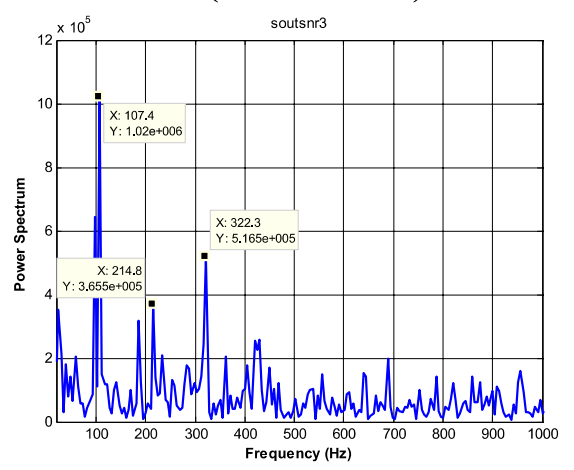

$(\mathrm{SNR}=\mathbf{0 . 3 8 4})$

(a)

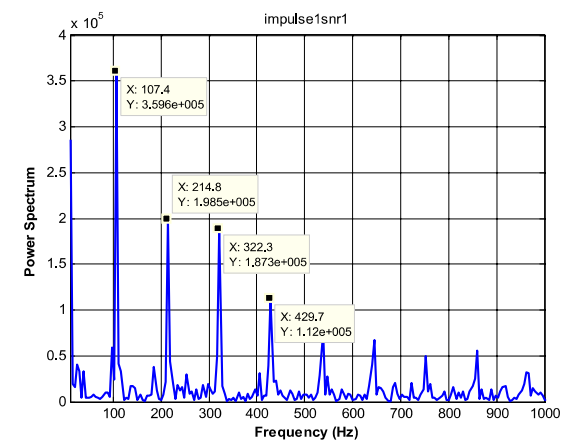

$(\tau=1 \%)$

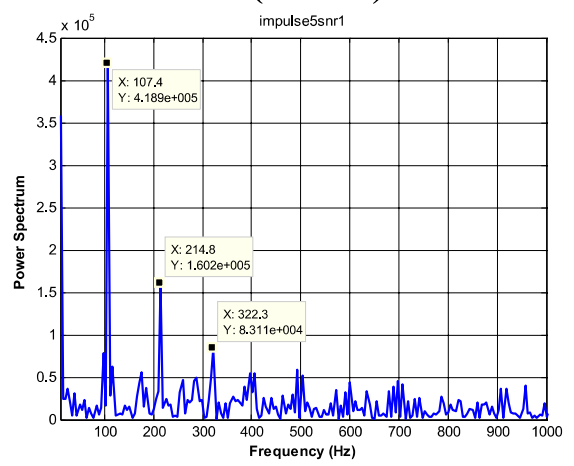

$(\tau=5 \%)$

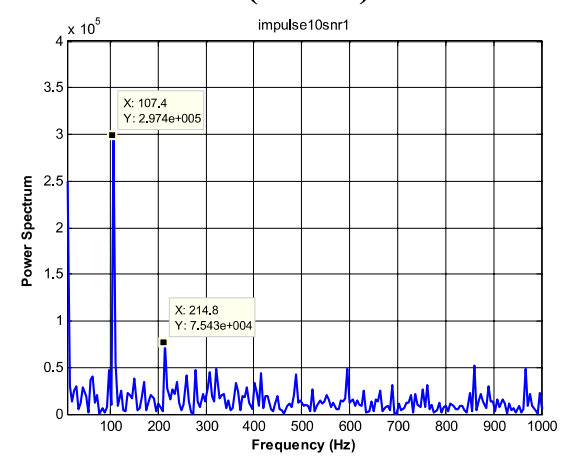

$(\tau=10 \%)$

(b)

Fig. 18. The TWPS for Bearing with outer-race fault for different (a) SNR, and (b) slip variation ( $\tau$ ).

\section{(b) Experimental vibration data}

For angular contact ball bearings with specifications as given in Table 2, the calculated fault frequencies for different shaft rotational speeds are shown in Table 3. With application of the 
TWPS, the power spectrum peak values at the location of the outer-race characteristic frequency and its harmonics are easily defined and match the calculated $F_{B P O}$, Figure 19. Applied to different shaft rotational speed, Figure 20 shows that the TWPS is sensitive to the variation of the fault frequencies as a result of variation in the shaft rotational speeds, Table 5 .

The TWPS for bearings with inner and rolling element faults are shown in Figures 21 and 22, respectively. The fault frequencies are clearly extracted at $126 \mathrm{~Hz}$ for inner race fault and $140.1 \mathrm{~Hz}$ for rolling element fault which are very close to the calculated fault frequencies.

\begin{tabular}{|c|c|c|}
\hline \multicolumn{3}{|c|}{ Outer-Race Fault } \\
\hline Shaft Speed, rev/min & Calculated FBPO, Hz & TWPS peak, Hz \\
\hline 1000 & 90.96 & 91 \\
\hline 1250 & 113.70 & 112 \\
\hline 1500 & 136.44 & 135 \\
\hline 1750 & 159.18 & 166 \\
\hline 2000 & 181.92 & 182 \\
\hline 2500 & 227.40 & 226 \\
\hline
\end{tabular}

Table 5. The calculated and extracted $\left(\mathrm{F}_{\mathrm{BPO}}\right)$ at different shaft rotational speeds.

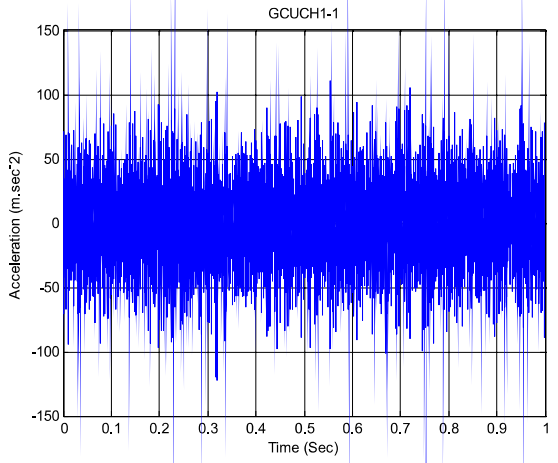

(a)

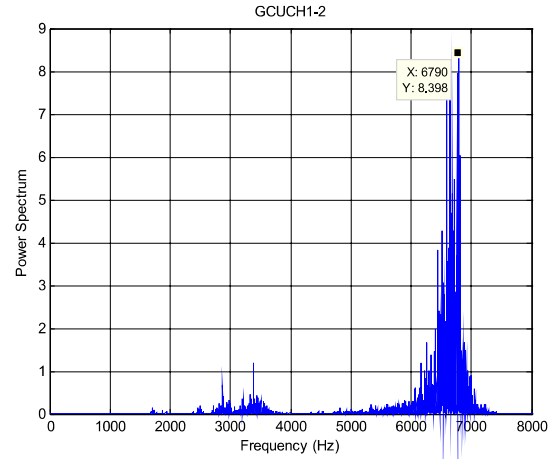

(b)

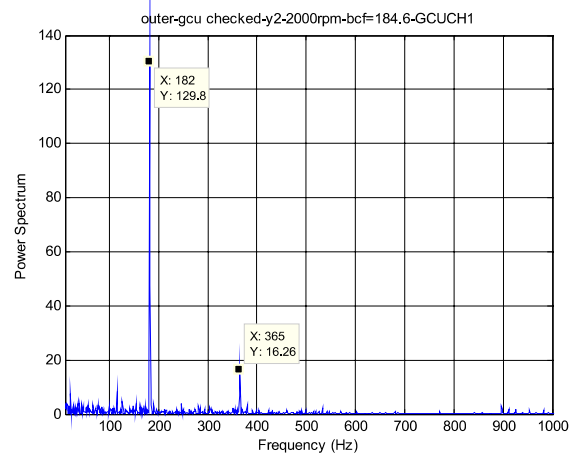

(c)

Fig. 19. The measured bearing vibration signal (a) the FFT spectrum (b) and the Laplace wavelet envelope spectrum (c) for bearing with outer race fault at speed of $2000 \mathrm{rev} / \mathrm{min}$ (calculated $\mathrm{F}_{\mathrm{BPO}}=181.92 \mathrm{~Hz}$ ). 

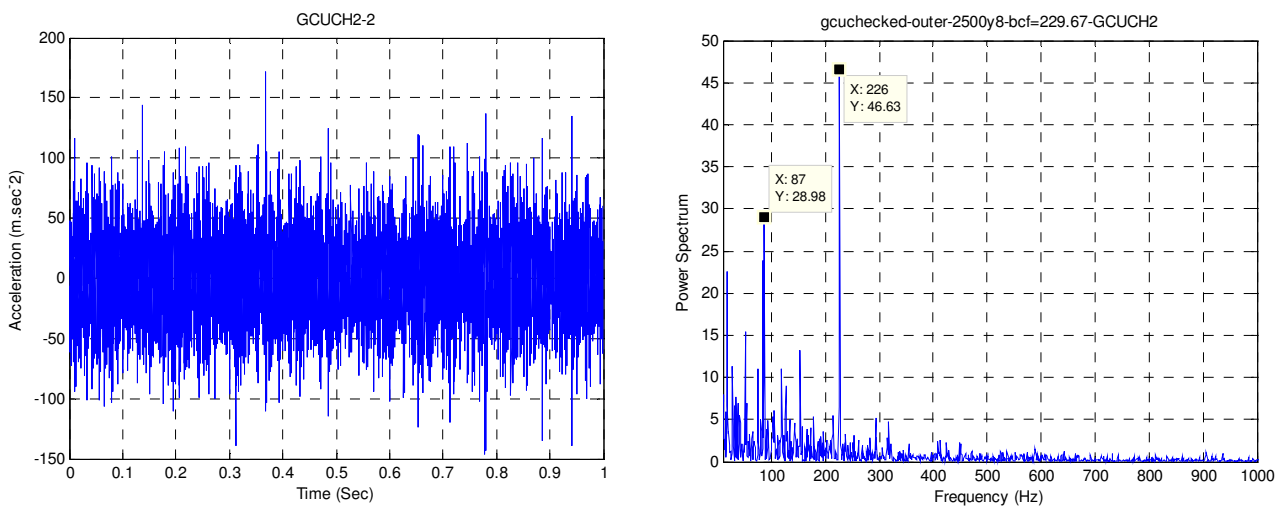

(a) $2500 \mathrm{rev} / \mathrm{min}$
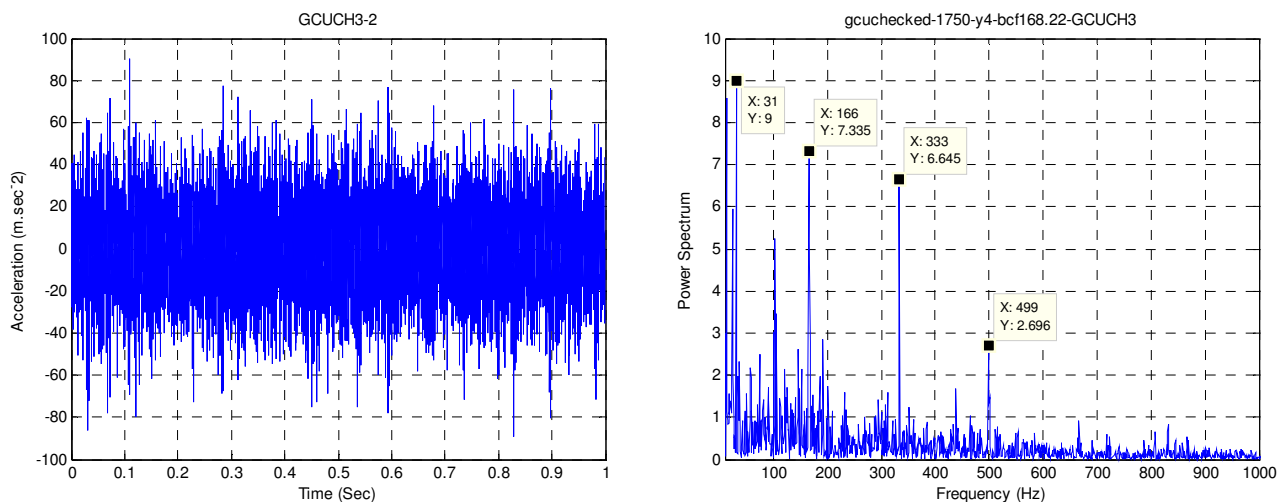

(b) $1750 \mathrm{rev} / \mathrm{min}$
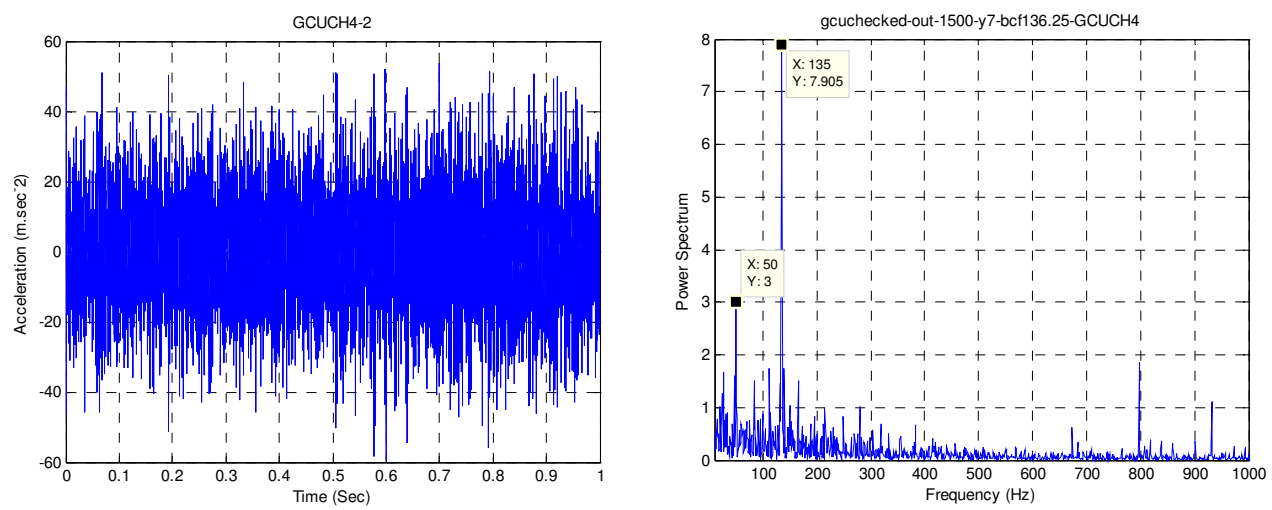

(c) $1500 \mathrm{rev} / \mathrm{min}$

Fig. 20. (a-e) the bearing vibration signals and the corresponding Laplace envelope spectrum column for bearing with outer race fault at different rotational speeds. 

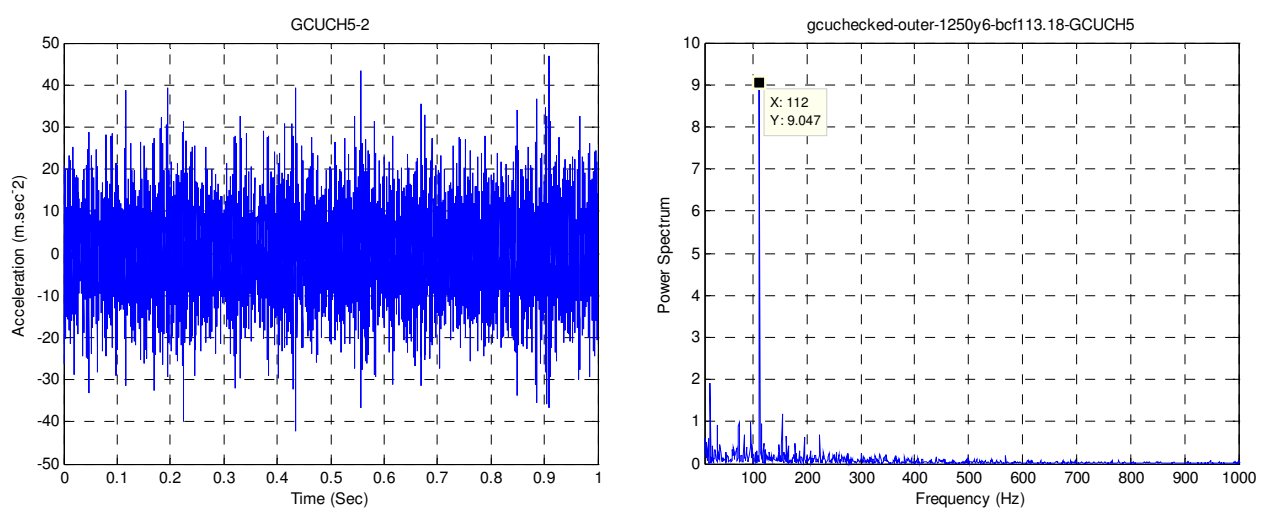

(d) $1250 \mathrm{rev} / \mathrm{min}$
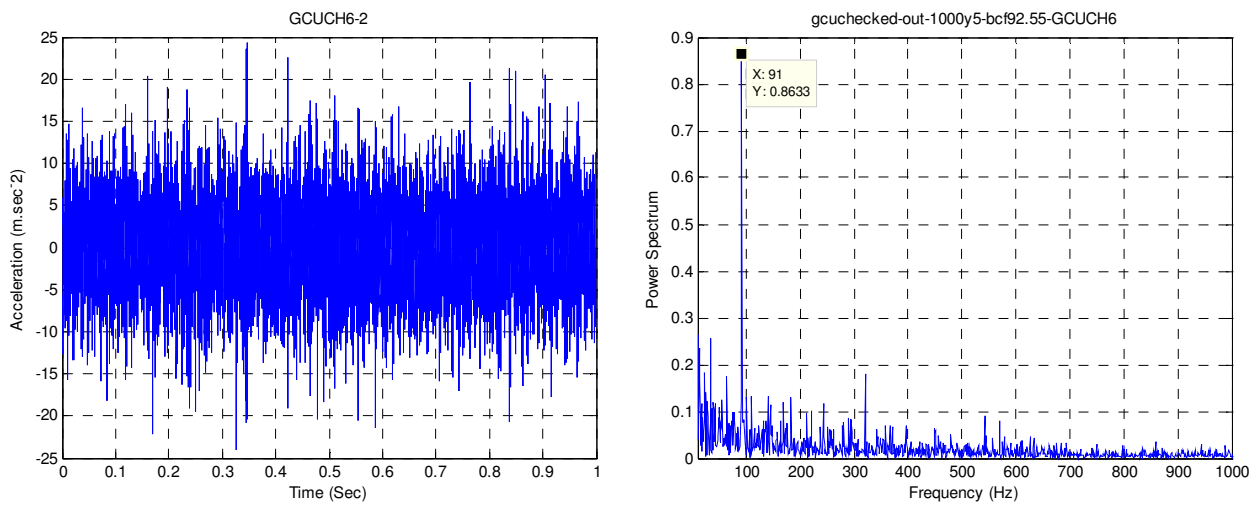

(e) $1000 \mathrm{rev} / \mathrm{min}$

Fig. 20. (cont.) (a-e) the bearing vibration signals and the corresponding Laplace envelope spectrum column for bearing with outer race fault at different rotational speeds. 


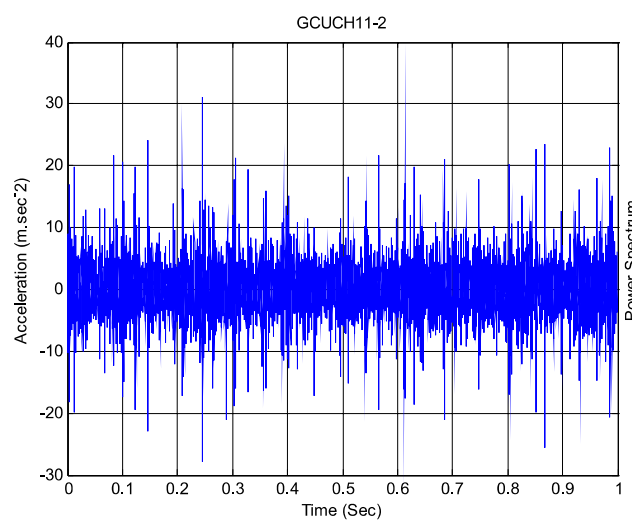

(a)

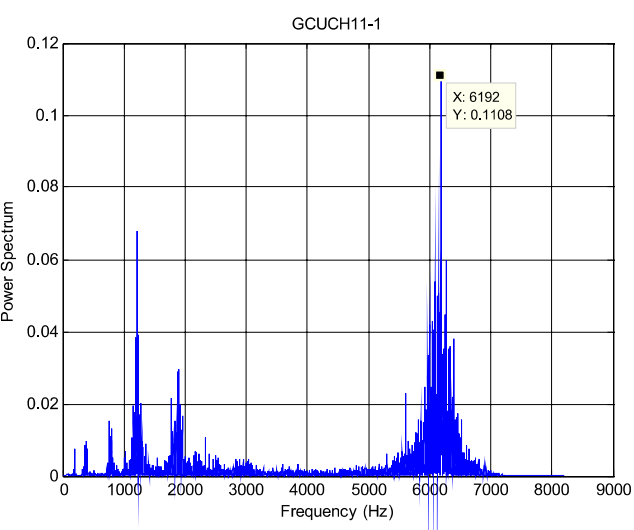

(b)

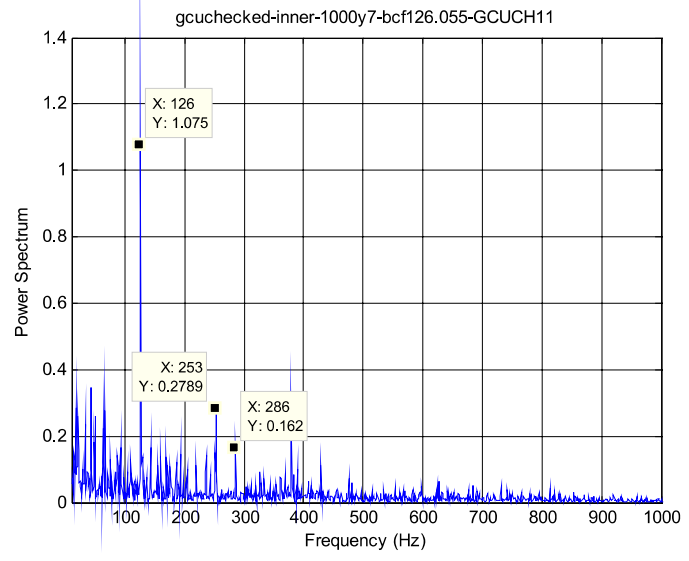

(c)

Fig. 21. The bearing vibration signal (a), the FFT spectrum (b) and the Laplace wavelet envelope spectrum (c) for bearing with inner race fault at speed of $1000 \mathrm{rev} / \mathrm{min}$ (the calculated $\mathrm{F}_{\mathrm{BPI}}=125.70 \mathrm{~Hz}$ ). 


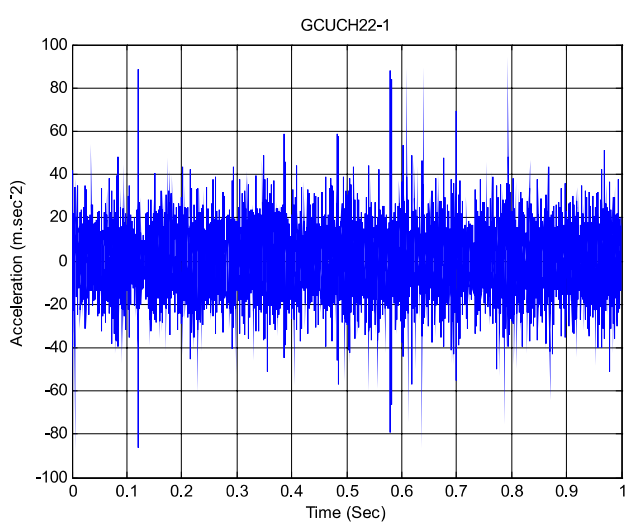

(a)

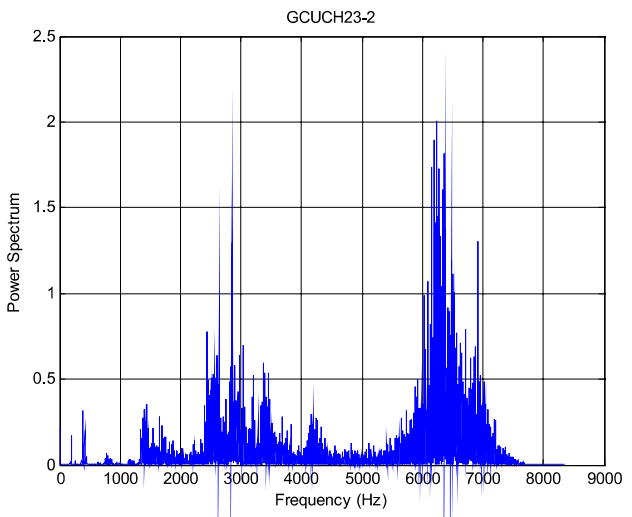

(b)

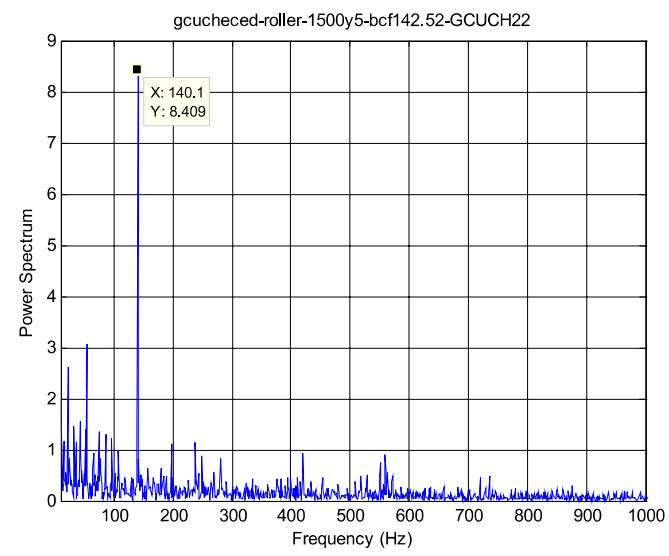

(c)

Fig 22. The bearing vibration signal (a), the FFT spectrum (b) and the Laplace wavelet envelope spectrum (c) for bearing with rolling element fault at speed of $1500 \mathrm{rev} / \mathrm{min}$ (the calculated, $2 \mathrm{~F}_{\mathrm{B}}=142.74 \mathrm{~Hz}$ ).

\section{(c) CWRU vibration data}

The time course of the vibration signals for a normal bearing and bearings with outer race, inner race and rolling element faults at a shaft rotational speed of $1797 \mathrm{rev} / \mathrm{min}$ with its corresponding TWPS are shown in Figures 23 to 26, respectively.

The TWPS for the vibration data shows spectral peaks at $106.9 \mathrm{~Hz}, 161.1 \mathrm{~Hz}$ and $141.166 \mathrm{~Hz}$ and their harmonics for outer race, inner race and rolling element faults, respectively. The sidebands at shaft speed $(30 \mathrm{~Hz})$ as a result of amplitude modulation are shown for inner and rolling element faults. 


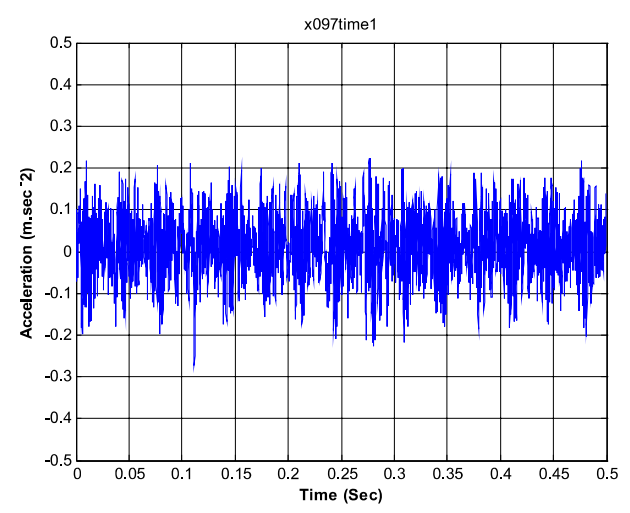

(a)

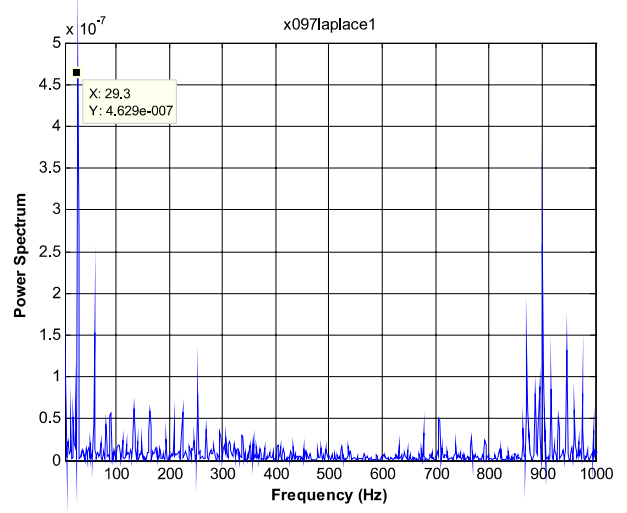

(b)

Fig. 23. The vibration signal (a), and the corresponding TWPS (b) for new rolling bearing (CWRU data).

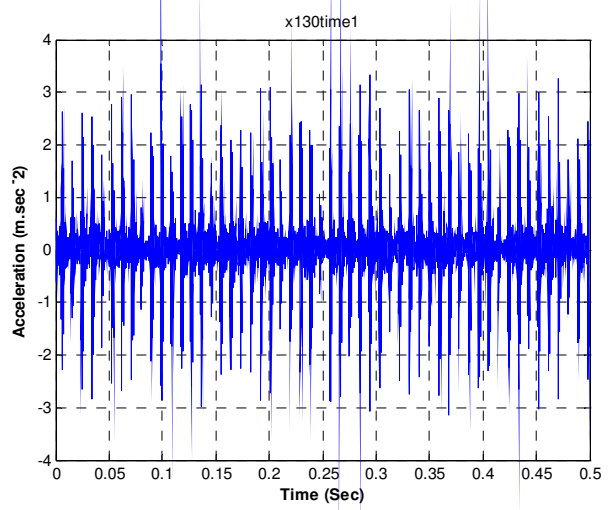

(a)

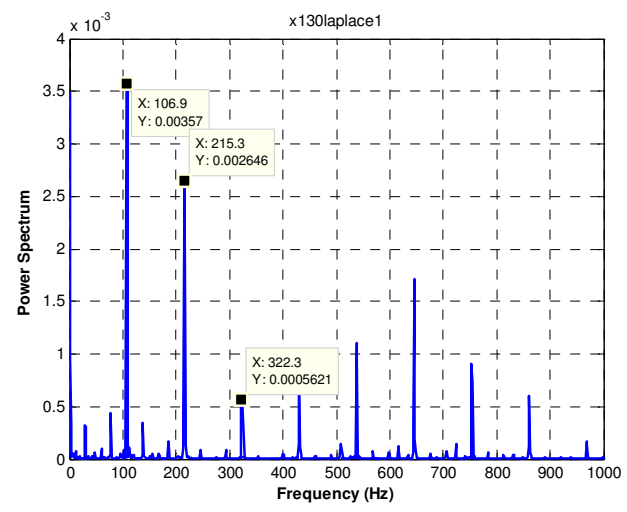

(b)

Fig. 24. The vibration signal (a) and, the corresponding TWPS (b) for rolling bearing with outer-race fault $\left(\mathrm{F}_{\mathrm{BPO}}=107.36 \mathrm{~Hz}\right)$. 


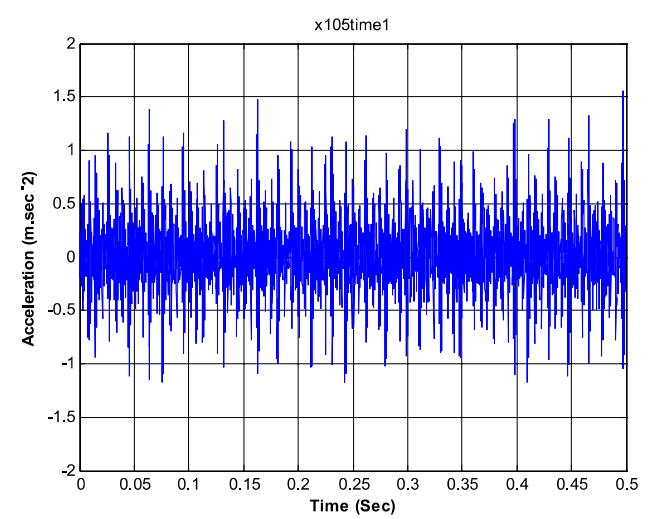

(a)

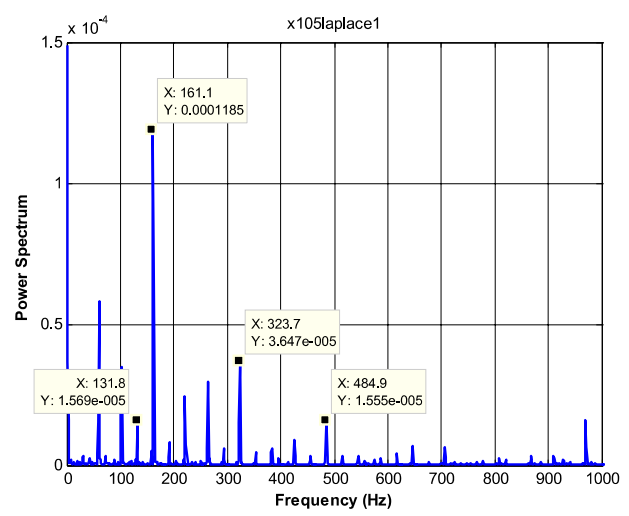

(b)

Fig. 25. The vibration signal (a), and the corresponding TWPS (b) for rolling bearing with inner-race fault $\left(\mathrm{F}_{\mathrm{BPI}}=162.185 \mathrm{~Hz}\right)$.

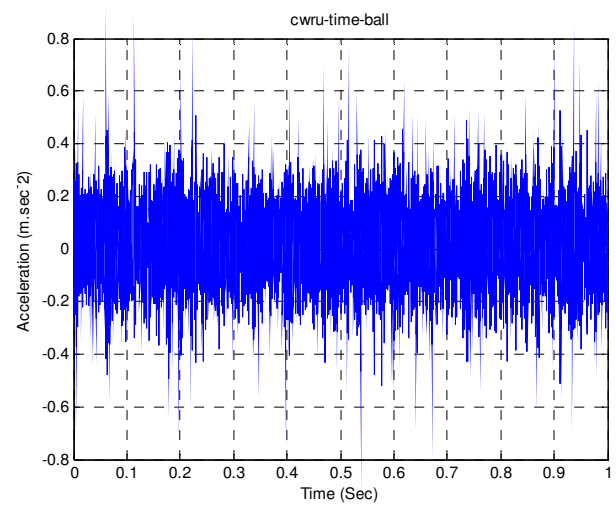

(a)

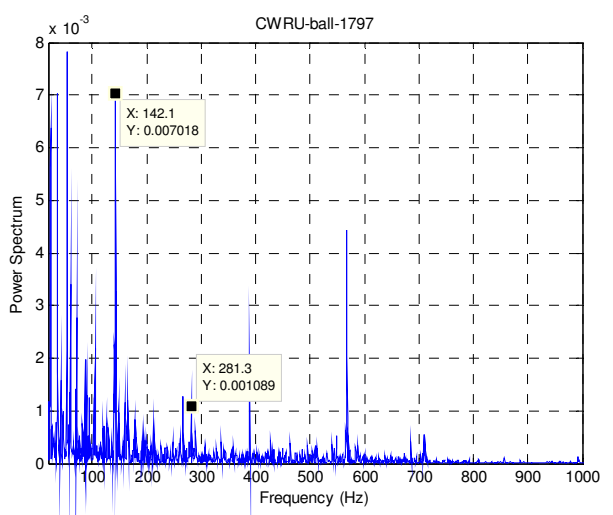

(b)

Fig. 26. The vibration signal (a), and the corresponding TWPS (b) for rolling bearing with rolling element fault $\left(2 \mathrm{~F}_{B}=141.166 \mathrm{~Hz}\right)$.

\section{Automatic rolling bearing fault diagnosis}

The interpolation of a CWT can certainly be accomplished by operator visual inspection with some practice and experience. However, computerized inspection is recommended to meet increasing demand for the on-line automated condition monitoring applications. 
In this section a new technique for automated detection and diagnosis of rolling bearing conditions is applied. To reduce the number of the ANN inputs and speed up the training process which make the classification procedure suitable for on-line condition monitoring and diagnostics, the most dominant Laplace-wavelet transform scales based on scalekurtosis level, which represent the most correlated features to the bearing condition, are selected for feature extraction. The extracted features in the time and frequency domains are used as the ANN input vectors for the rolling bearing condition identification. The ANN classifier parameters (learning rate parameter and number of the hidden nodes) are optimized using GA by minimizing the mean square error (MSE).

\subsection{Feature extraction using laplace wavelet analysis}

The predominant Laplace wavelet transform scales (most informative levels) based on the scale-kurtosis value have been selected for feature extraction. Figure 27 shows the scalekurtosis distribution for different bearing conditions with the corresponding wavelet scale threshold. By using the maximum kurtosis for a normal bearing as a threshold level (the dotted line in Figure 27) for the wavelet scales, it could be seen that the scales range of 12-22 are the mostly dominant scales which can reveal the rolling bearing condition sufficiently.

The extracted features for the dominant scales are:

1. Time domain features: this includes the Root Mean Square (RMS), Standard Deviation (SD), and Kurtosis factor.

2. Frequency domain features: this includes the WPS peak frequency $\left(f_{\max }\right)$ to the shaft rotational frequency $\left(f_{r p m}\right)$ ratio, and the WPS maximum amplitude $\left(A_{\max }\right)$ to the overall amplitude (Sum $\left.\left(A_{i}\right)\right)$ ratio.

The extracted features were linearly normalized between $[0,1]$ using the relationship: $x_{\text {nor }}=$ $\left.\left[\left(x-x_{\min }\right) / x_{\max }\right)\right]$, and used as input vectors to the neural network.

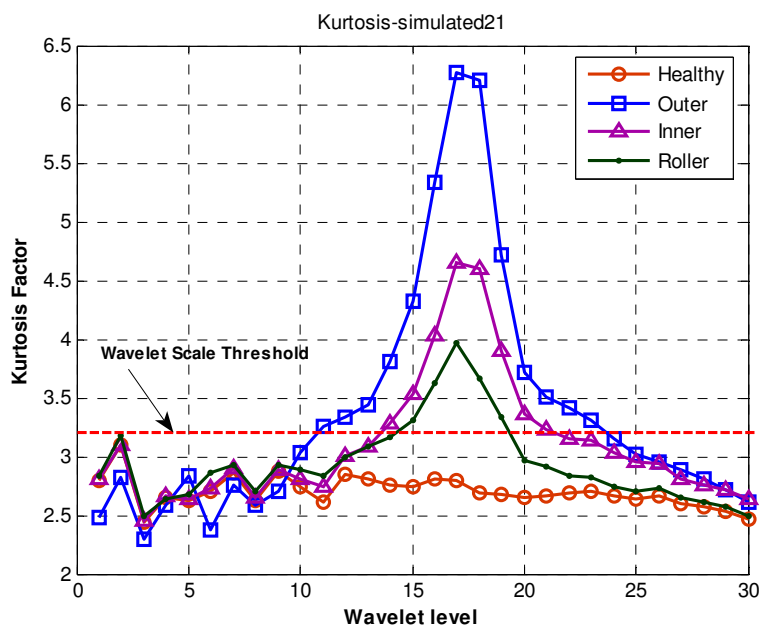

Fig. 27. The Kurtosis distribution for the Laplace wavelet transforms scales using Laplace wavelet. 


\subsection{Neural networks scheme}

A feed-forward multi-layer perceptron (MLP) neural network has been developed, which consists of three layers. The input layer of five source nodes represents the normalized features extracted from the predominant Laplace wavelet transform scales. The hidden layer with four computation nodes has been used. The number of the hidden nodes is optimized using a genetic algorithm by minimization of Mean Square Error (MSE) between the actual network outputs and the corresponding target values. The output layer with four nodes represents the different bearing working conditions to be identified by the neural network.

The four-digit output target nodes that need to be mapped by the ANN are distinguished as: $(1,0,0,0)$ for a new bearing $(\mathrm{NB}),(0,1,0,0)$ for a bearing with outer race fault (ORF), $(0$, $0,1,0)$ for an inner race fault (IRF), and $(0,0,0,1)$ for a rolling element fault (REF). Figure 628a depicts the overall architecture of the proposed diagnostic system.

The training sample vector comprises the extracted features and the ideal target outputs expressed by $\left[x_{1}, x_{2}, x_{3}, x_{4}, x_{5}, T\right] T$, where $x_{1}-x_{5}$ represent the input extracted features, and $T$ is the four-digit target output.

The input vector is transformed to an intermediate vector of hidden variables $h$ using the activation function $f_{1}$, Figure 2-28b. The output $h_{j}$ of the $j^{\text {th }}$ node in the hidden layer is obtained as follows,

$$
h_{j}=f_{1}\left(\sum_{i=1}^{N=5} w_{i, j} x_{i}+b_{j}\right)
$$

Where $b_{j}$ and $w_{i, j}$ represent the bias and the weight of the connection between the $j^{\text {th }}$ node in the hidden layer and the $i^{\text {th }}$ input node respectively.

The output vector $O=\left(\begin{array}{lll}o_{1} & o_{2} \ldots o_{M}\end{array}\right)$ of the network is obtained from the vector of the intermediate variable $h$ through a similar transformation using activation function $f_{2}$ at the output layer, Figure 2-28c. For example, the output of neuron $k$ can be expressed as follows:

$$
O_{k}=f_{2}\left(\sum_{l=1}^{M=4} w_{l, k} h_{l}+b_{k}\right)
$$

The training of an MLP network is achieved by modifying the connection weights and biases iteratively to optimize a performance criterion. One of the widely used performance criteria is the minimization of the mean square error (MSE) between the actual network output $\left(O_{k}\right)$ and the corresponding target values $(T)$ in the training set. The most commonly used training algorithms for MLP are based on back-propagation (BP). The BP adapts a gradient-descent approach by adjusting the ANN connection weights. The MSE is propagated backward through the network and is used to adjust the connection weights between the layers, thus improving the network classification performance. The process is repeated until the overall MSE value drops below some predetermined threshold (stopping criterion). After the training process, the ANN weights are fixed and the system is deployed to solve the bearing condition identification problem using unseen vibration data. 


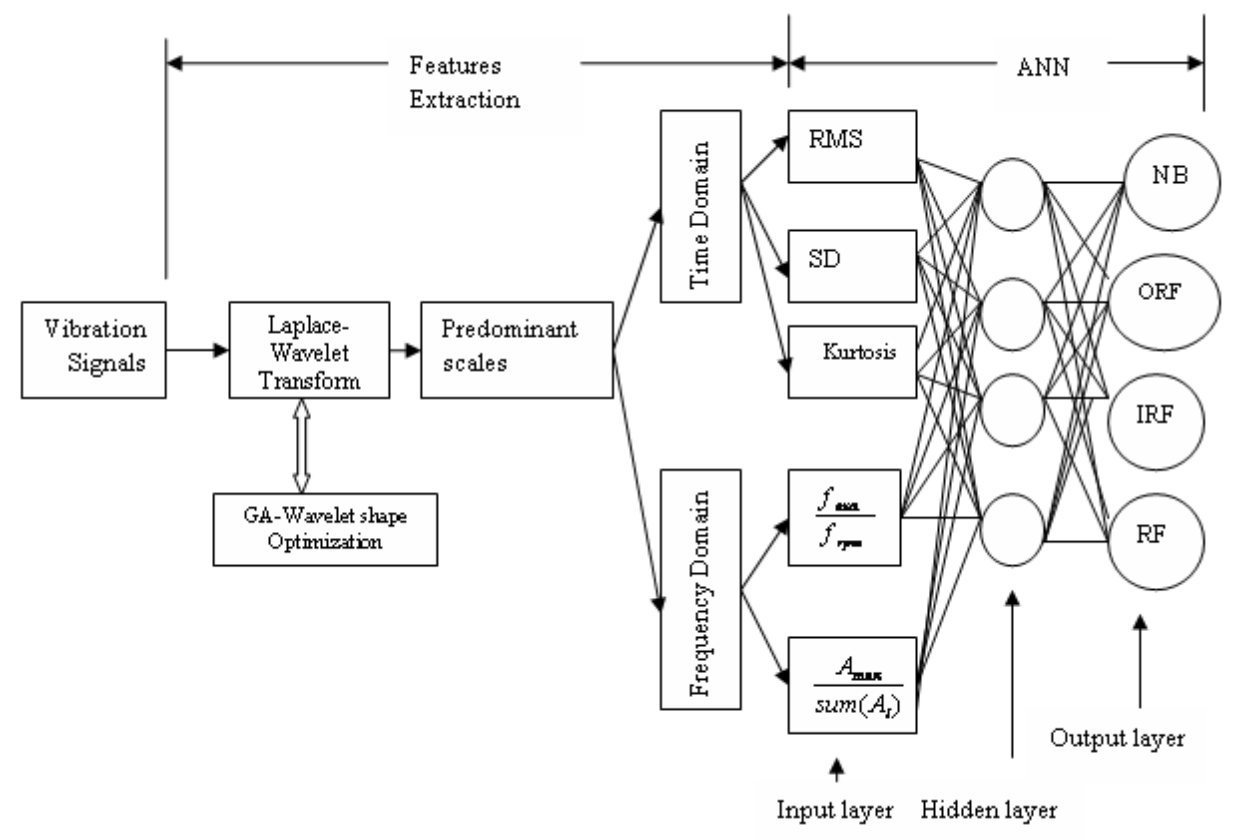

(a)

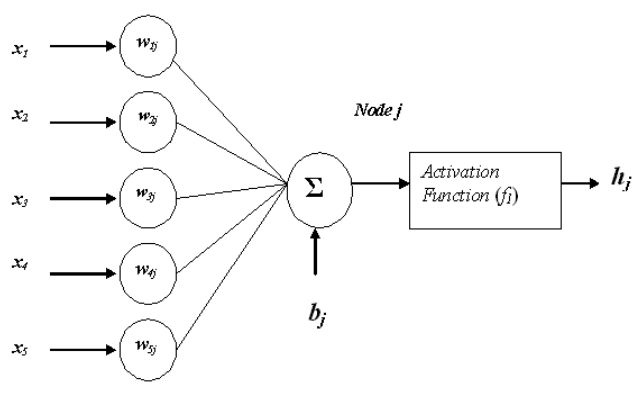

(b)

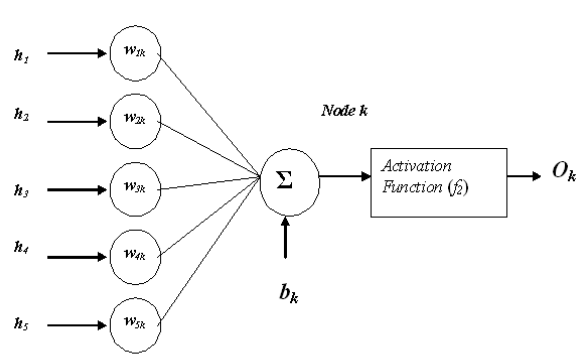

(c)

Fig. 28. (a) the applied diagnosis system, (b) the input and hidden layer, and (c) the hidden and output layer.

The ANN was created, trained and tested using MATLAB Neural Network Toolbox with Levenberg-Marquarat Back-propagation (LMBP) training algorithm. In this work, A MSE of 10E-20, a minimum gradient of 10E-10 and maximum iteration (epochs) of 1000 were used. The training process would stop if any of these conditions were met. The initial weights and biases of the network were randomly generated by the program. 


\subsection{Implementation of WPS -ANN for bearing fault classification}

The derived WT-ANN fault classification technique was validated through real and simulated rolling element bearing vibration signals. MATLAB software has been used for the wavelet feature extraction and ANN classification based on the code flowchart shown in Figure 29.

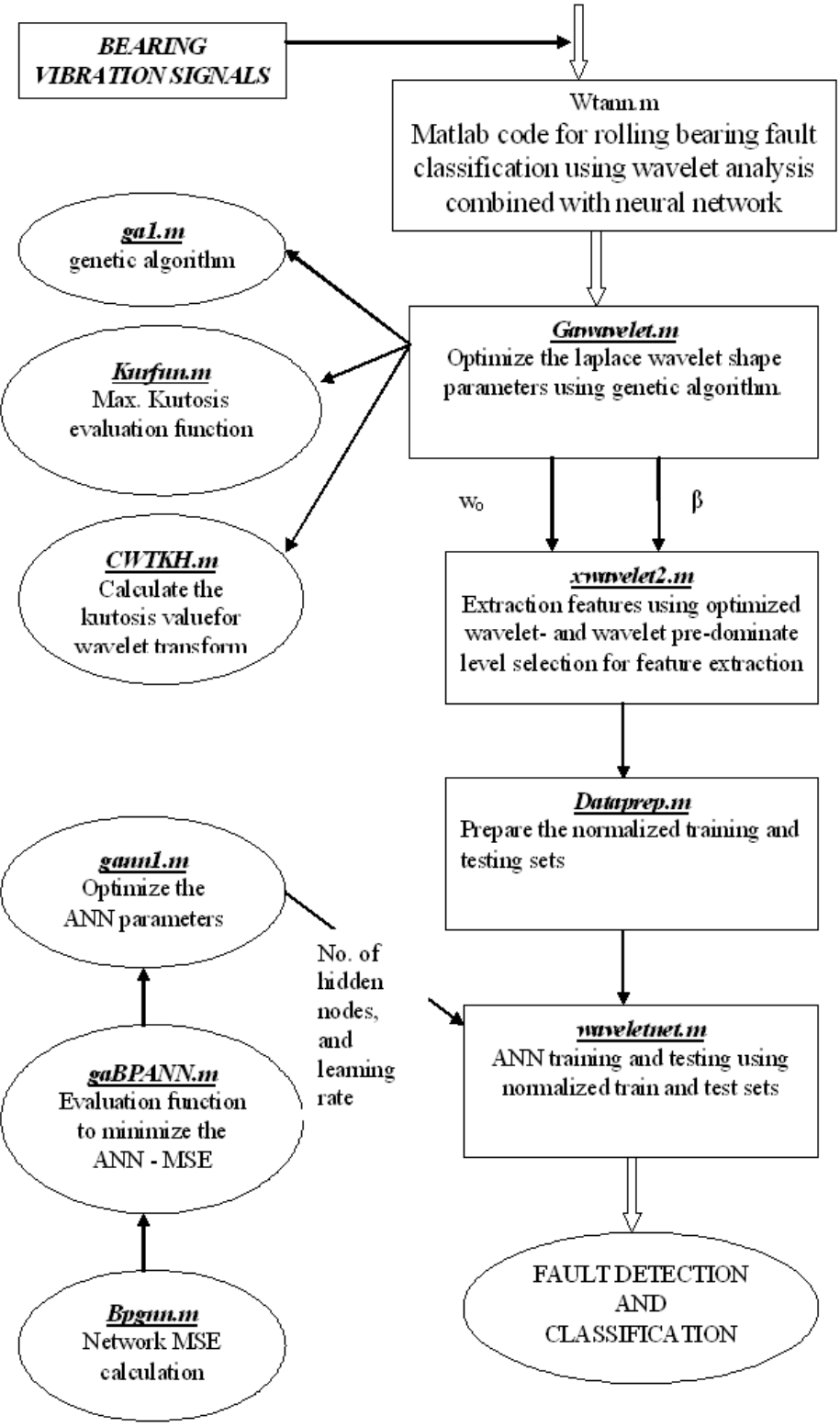

Fig. 29. WT-ANN automatic bearing fault diagnosis MATLAB codes flow chart. 


\section{(a) The CWRU vibration data}

The smallest fault diameter which introduce smallest fault pulse amplitudes is selected in this study at two different shaft rotational speeds of $1797 \mathrm{rev} / \mathrm{min}$ (with no motor load condition) for training data and $1772 \mathrm{rev} / \mathrm{min}$ (with $1 \mathrm{HP}$ motor load) for the test data.

The neural network input feature vectors consist of five groups representing the different bearing conditions, a total of 3856 segments of 1000 samples each. The data sets were split between training and test (unseen) sets of size 1928 samples each. The parameters of the applied BP neural network are listed in Table 6.

\begin{tabular}{|c|c|c|c|c|}
\hline \multicolumn{5}{|c|}{ Neural Network architecture } \\
\hline \multicolumn{2}{|c|}{ Transfer Function } & \multirow{2}{*}{$\begin{array}{l}\text { No. of input } \\
\text { nodes }\end{array}$} & \multirow{2}{*}{$\begin{array}{c}\text { Hidden layer } \\
\text { nodes }\end{array}$} & \multirow{2}{*}{$\begin{array}{c}\text { No. of output } \\
\text { nodes }\end{array}$} \\
\hline $\begin{array}{l}\text { Hidden } \\
\text { Layer }\end{array}$ & $\begin{array}{c}\text { Output } \\
\text { Layer }\end{array}$ & & & \\
\hline Sigmoid & Linear & 5 & 4 & 4 \\
\hline \multicolumn{5}{|c|}{ NN Training parameters } \\
\hline \multicolumn{2}{|c|}{ Training Algorithms } & Learning rate & \multicolumn{2}{|c|}{ Training Stop Criteria } \\
\hline \multirow{2}{*}{\multicolumn{2}{|c|}{ LM }} & \multirow{2}{*}{0.52} & Max. epoch & MSE \\
\hline & & & 1000 & 10E-20 \\
\hline
\end{tabular}

Table 6. Applied neural network architecture and training parameters.

The distribution of the extracted features (normalized between 0 and 1), time domain features (RMS and kurtosis) on x-axis and frequency domain features $\left(f_{\max } / f_{\text {rpm }}\right.$ and $\left.A_{\max } / \operatorname{sum}(A)\right)$ on the y-axis, for the most dominant scales of the Laplace wavelet transform for different rolling bearing fault conditions is shown in Figure 30a. It is clear that the normalized feature values for the bearing with outer-race fault are the highest as a result of the high energy fault pulses compared with the less energy pulses generated by inner-race and roller faults as a consequence of amplitude modulation.

The result of the learning process of the developed NN is depicted in Figure 30b, which shows that the training with 300 iterations met the MSE stopping criteria (MSE less than 10E-20). The NN test process for unseen vibration data of the trained ANN combined with the ideal output target values are presented in Figure 30d, which indicates the high success classification rate $(\approx 100 \%)$ for rolling bearing fault detection and classification. 


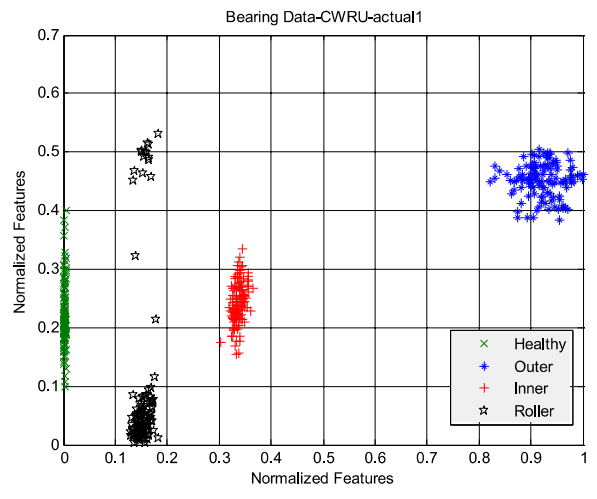

(a)

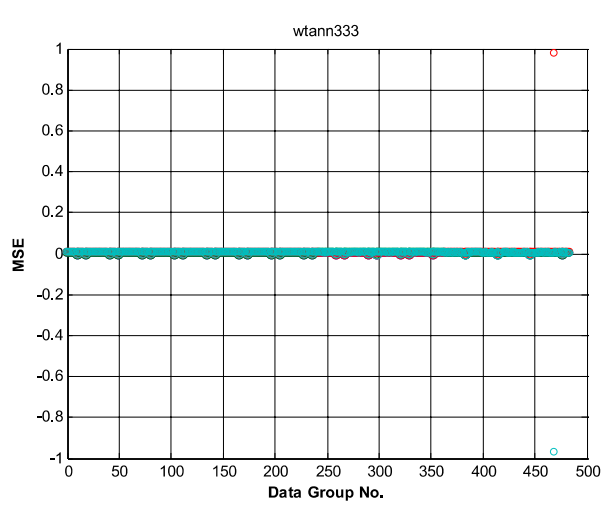

(c)

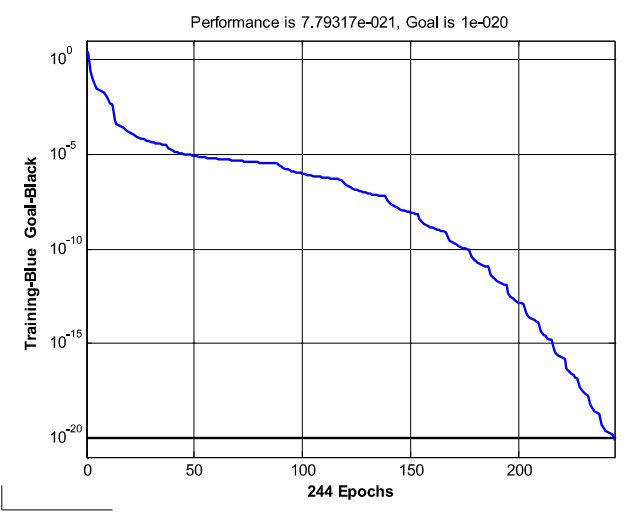

(b)

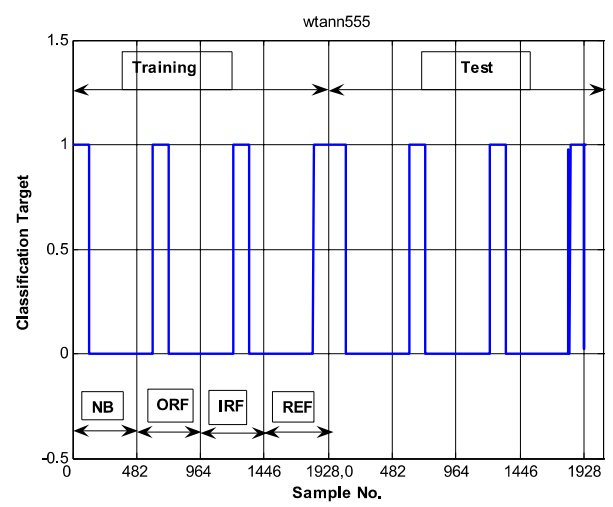

(d)

Fig. 30. (a) the extracted features distribution, (b) ANN learning process, (c) ANN classification MSE, (d) ANN Training/Test process, for the CWRU bearing vibration data.

\section{(b) Simulated vibration data}

Using the same bearing specifications but CWRU data with $0.6 \mathrm{~dB}$ signal to noise ratio and random slip of 10 percent the period T. Figure 31 shows the Wavelet-ANN bearing fault training/classification process for the simulated bearing vibration signal. The results show that the Wavelet-ANN training process reached the specified stopping criteria after 67 epochs, with overall classification MSE less than 6.0E-9, and 100\% classification rate. 


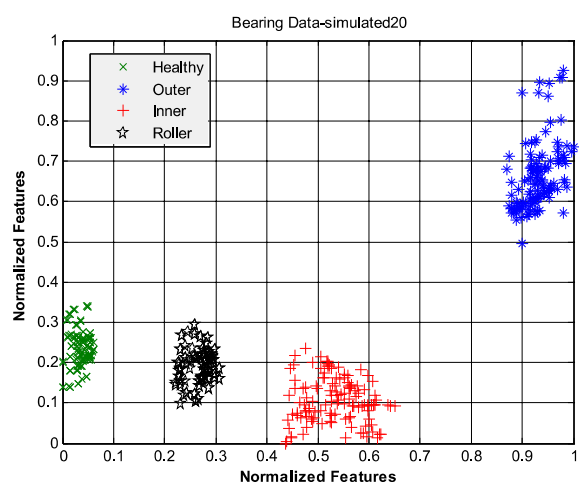

(a)

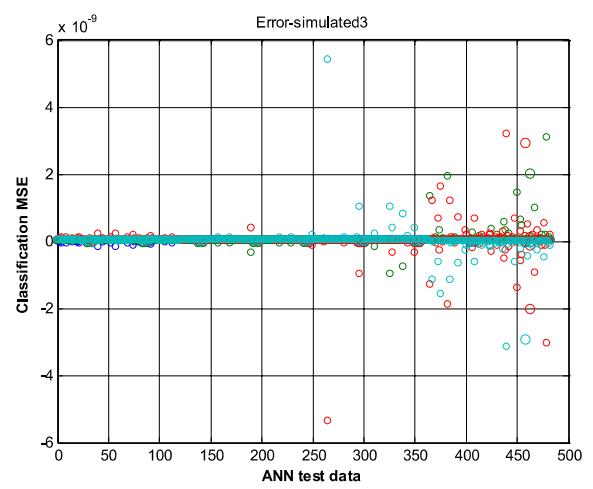

(a)

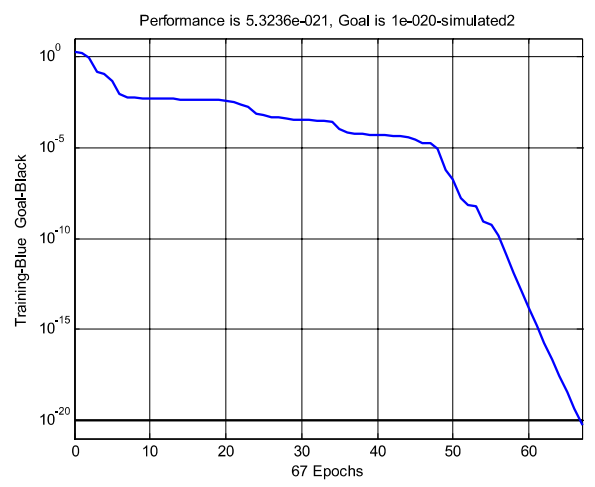

(b)

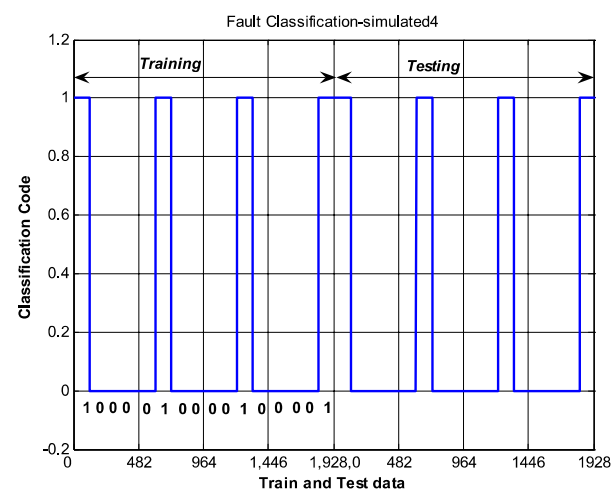

(b)

Fig. 31. (a) the extracted features distribution, (b) ANN learning process, (c) ANN classification MSE, and (d) ANN Training / Test process, for the simulated bearing vibration data.

\section{(c) Experimental vibration data}

The ANN training sets have been prepared using an acquired vibration signal at a shaft speed of $1000 \mathrm{rev} / \mathrm{min}$, and the ANN testing set at a shaft speed of $1250 \mathrm{rev} / \mathrm{min}$. Figure 32 shows the Wavelet-ANN bearing fault training/classification process for the measured bearing vibration signals. The results show that the Wavelet-ANN training process achieved the specified stopping criteria after 28 epochs, with overall classification MSE less than 6.0E5 with $100 \%$ classification rate. 


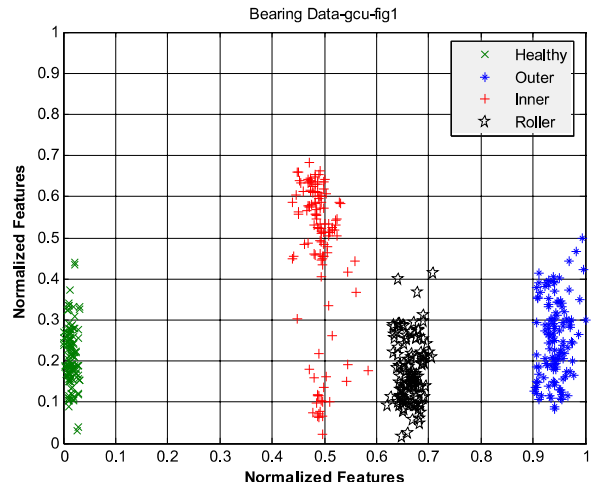

(a)

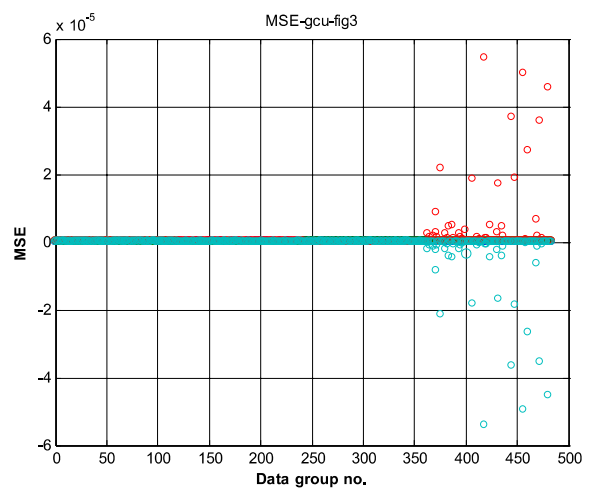

(c)

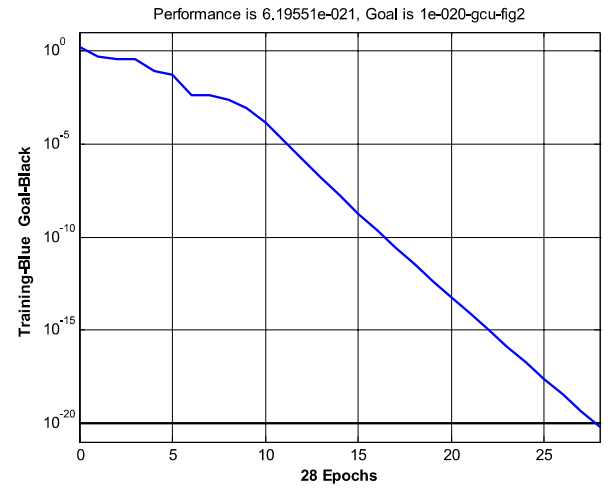

(b)

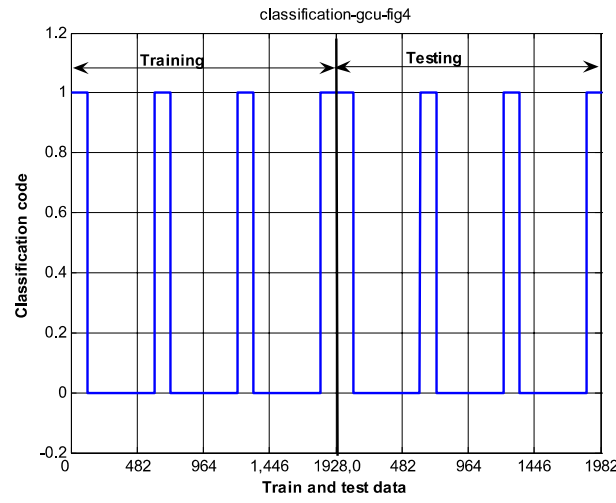

(d)

Fig. 32. (a) the extracted features distribution, (b) ANN learning process, (c) ANN classification MSE, and (d) ANN Training / Test process, for the experimental bearing vibration data.

The results for both the simulated and real bearing vibration data show the effectiveness of the combined wavelet-ANN technique for rolling bearing fault pattern detection and classification, and that the Laplace wavelet analysis is an effective approach in fault feature extraction for the NN classifier.

\section{Conclusions}

The novelty of this chapter is concerned with the applications of the wavelet analysis in two different new approaches: 
- Firstly, the impulse wavelet is used as a de-noising technique to extract the fault pulses buried in the noisy signal for fault detection, and by evaluating the periodicity of these pulses through the calculation of the autocorrelation function the location of the fault can be identified.

- Secondly, the implementations of the complex Laplace wavelet for

- Bearing fault detection through the evaluation of the wavelet envelope power spectrum.

- Automatic bearing fault detection and diagnosis through the extraction of the input feature vectors to the NN classifier.

From the above wavelet applications the following points can be concluded:

a. The use of the wavelet analysis provides more information related to the bearing fault detection compared with the FFT frequency spectrum which can be used only for a stationary signal. Also the use of a shifted and scaled wavelet window over the analyzed signal produces better detection capabilities than that of the fixed size window used in the STFT.

b. The use of a wavelet base function with more similarity with the fault feature leads to enhance the wavelet analysis and generates wavelet coefficients with more information related to the bearing fault and as a result the efficiency of the fault diagnosis process can be increased. In this project the optimized Impulse wavelet and Laplace wavelet are used as new wavelet functions for fault detection and feature extraction.

c. The use of more informative features as input vectors to the NN classifier can speed up the classification process and increase its accuracy by reducing the size of the NN through decrease of the input vectors and the hidden layers and nodes.

Compared with the previously conducted researches that used the normal time and/or frequency domain features as NN input vectors, the use of the wavelet analysis for feature extraction produces a most efficient classifier of the bearing faults with less input features. Furthermore, the use of the optimized wavelet and the most dominant wavelet coefficients in the feature extraction process leads to increase the accuracy and the success rate of the NN classifier.

d. The bearing vibration signals obtained from the bearing simulation model that take into account the effects of the amplitude modulation and the slippage effects which are the main causes of non-stationary bearing signals, can be used to evaluate the performance of the proposed detection techniques with different simulated working conditions.

\section{Appendix (A): Bearing rotational frequencies}

In general, the bearing inner race is attached to a shaft and therefore has the same rotational frequency as the shaft $\left(F_{s}\right)$ while the outer race can be assumed stationary, since it is generally locked in place by an external casing (i.e. it has a constant rotational frequency of zero). The bearing rotational frequencies can be obtained as follows (Figure 1-7):

\subsection{Cage Frequency $\left(F_{C}\right)$}

The rotational frequency of the cage can be expressed in terms of the pitch circle diameter $\left(D_{p}\right)$, the diameter of the rolling element $\left(D_{b}\right)$ and the contact angle $(a)$ as: 


$$
F_{C}=\frac{F_{s}}{2}\left(1-\frac{D_{b}}{D_{p}} \cos \alpha\right)
$$

\subsection{Ball Pass Frequencies $\left(F_{B P I}, F_{B P O}\right)$}

The rolling element (ball or roller) pass frequencies are the rate at which rolling elements pass a point on the track of the inner or outer race. Given the number of rolling elements $\left(N_{b}\right)$, the theoretical balls (or rolling element) pass frequencies are:

The inner race ball passes frequency $\left(F_{B P I}\right)$,

$$
F_{B P I}=\frac{F_{s}}{2}\left(1+\frac{D_{b}}{D_{p}} \cos \alpha\right) N_{b}
$$

And the outer race ball passes frequency $\left(F_{B P O}\right)$,

$$
F_{B P O}=\frac{F_{s}}{2}\left(1-\frac{D_{b}}{D_{p}} \cos \alpha\right) N_{b}
$$

\subsection{Ball Spins Frequency $\left(F_{B}\right)$}

The ball (or roller) spin frequency is the frequency at which a point on the rolling element contacts with a given race (inner or outer race), and given by:

$$
F_{B}=\frac{F_{s}}{2} \frac{D_{p}}{D_{b}}\left(1-\left(\frac{D_{b}}{D_{p}} \cos \alpha\right)^{2}\right)
$$

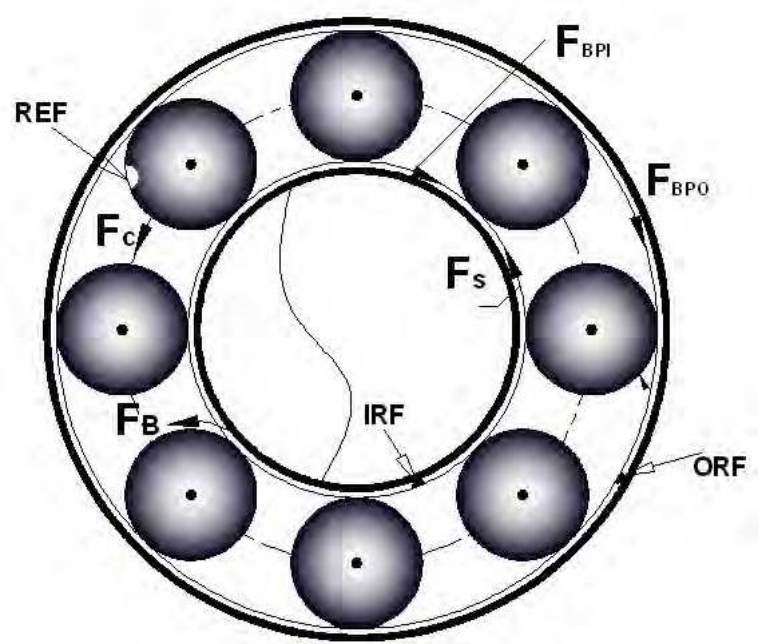

Fig. A1. Basic frequencies and faults in a rolling element bearing. 


\section{References}

Junsheng, C., Dejie, Y. and Yu, Y. (2007): “Application of an impulse response wavelet to fault diagnosis of rolling bearings", Mechanical systems and signal processing, vol. 21, pp. 920-929.

Kahaei, M. H., Torbatian, M. and Poshtan, J. (2006): “Detection of Bearing Faults Using Haar Wavelets", IEICE Transaction fundamentals, vol.E89a (3), pp.757-763.

Khalid F. Al-Raheem, Roy, A., Ramachandran, K. P., Harrison, D.K. and Grainger, S. (2008):"Application of Laplace Wavelet Combined with Artificial Neural Networks for Rolling Element Bearing Fault Diagnosis", ASME J. of vibration and Acoustics, Vol.130 (5), pp. 051007(1)-051007(9).

Khemili, I. and Chouchane, M. (2005): "Detection of rolling element bearing defects by adaptive filtering", European Journal of Mechanics and Solids, vol.24, pp. 293-303.

Lind, R. and Brenner, M. J. (1998): “Correlation filtering of modal dynamics using the Laplace wavelet". NASA Dryden Flight Research center Edwards CA 93523-0273, pp.1-10.

Mallat, S. (1999): a wavelet tour of signal processing, 2nd edition, Academic Press.

Orhan, S., Akturk, N. and Celik, V. (2006): “Vibration monitoring for defect diagnosis of rolling element bearings as a predictive maintenance tool: comprehensive case studies", NDT E E International, vol.39, pp. 293-298.

Peng, Z.K. and Chu, F.L. (2004): "Application of the wavelet transform in machine condition monitoring and fault diagnostics: a review with bibliography", Mechanical systems and signal processing, vol. 18, pp. 199-221.

Reeves T. (1994): "Failure modes of rolling element bearings", Proceedings of $8^{\text {th }}$ annual meeting vibration inst., pp. 209-217.

Tandon N. (1994), "A comparison of some vibration parameters for the condition monitoring of rolling element bearings", Measurements, vol.12, pp.285-289.

Thanagasundram, S. and Schlindwein, F. S. (2006): "Auto-regression based diagnostics scheme for detection of bearing faults", Proceeding of ISMA, pp. 3531-3546.

Wang, C. and Gao, R. X. (2003): "Wavelet transform with spectral post-processing for enhanced feature extraction", IEEE transactions on instrumentation and measurement, vol.52 (4), pp. 1296-1301.

Weller, N. (2004): “Acceleration enveloping- higher sensitivity- earlier detection”, Machinery message.

Yang, W. and Ren, X. (2004): "Detecting Impulses in Mechanical Signals by Wavelets", EURASIP Journal on Applied Signal Processing, vol.8, pp.1156-1162.

Yanyang, Z., Xuefeng, C., Zhengjia, H. and Peng, C. (2005): “Vibration based Modal Parameters Identification and wear fault diagnosis using Laplace wavelet", Key Engineering Materials, vol. 293-294, pp.183-190. 


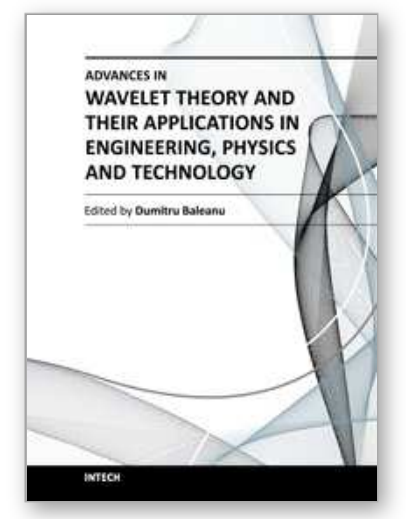

\author{
Advances in Wavelet Theory and Their Applications in \\ Engineering, Physics and Technology \\ Edited by Dr. Dumitru Baleanu
}

ISBN 978-953-51-0494-0

Hard cover, 634 pages

Publisher InTech

Published online 04, April, 2012

Published in print edition April, 2012

The use of the wavelet transform to analyze the behaviour of the complex systems from various fields started to be widely recognized and applied successfully during the last few decades. In this book some advances in wavelet theory and their applications in engineering, physics and technology are presented. The applications were carefully selected and grouped in five main sections - Signal Processing, Electrical Systems, Fault Diagnosis and Monitoring, Image Processing and Applications in Engineering. One of the key features of this book is that the wavelet concepts have been described from a point of view that is familiar to researchers from various branches of science and engineering. The content of the book is accessible to a large number of readers.

\title{
How to reference
}

In order to correctly reference this scholarly work, feel free to copy and paste the following:

Khalid Al-Raheem (2012). Wavelet Analysis and Neural Networks for Bearing Fault Diagnosis, Advances in Wavelet Theory and Their Applications in Engineering, Physics and Technology, Dr. Dumitru Baleanu (Ed.), ISBN: 978-953-51-0494-0, InTech, Available from: http://www.intechopen.com/books/advances-in-wavelettheory-and-their-applications-in-engineering-physics-and-technology/wavelet-analysis-and-neural-networksfor-bearing-fault-diagnosis

\section{INTECH}

open science | open minds

\author{
InTech Europe \\ University Campus STeP Ri \\ Slavka Krautzeka 83/A \\ 51000 Rijeka, Croatia \\ Phone: +385 (51) 770447 \\ Fax: +385 (51) 686166 \\ www.intechopen.com
}

\author{
InTech China \\ Unit 405, Office Block, Hotel Equatorial Shanghai \\ No.65, Yan An Road (West), Shanghai, 200040, China \\ 中国上海市延安西路65号上海国际贵都大饭店办公楼 405 单元 \\ Phone: +86-21-62489820 \\ Fax: +86-21-62489821
}


(C) 2012 The Author(s). Licensee IntechOpen. This is an open access article distributed under the terms of the Creative Commons Attribution 3.0 License, which permits unrestricted use, distribution, and reproduction in any medium, provided the original work is properly cited. 